\title{
El jaciment de la Devesa (el Vendrell): un exemple d'explotació agrícola al Baix Penedès
} (ager Tarraconensis)

\section{The archaeological site of La Devesa (El Vendrell): an example of a farming settlement in Baix Penedès (Ager Tarraconensis)}

L'any 2014 una intervenció arqueològica preventiva al municipi penedesenc del Vendrell va permetre documentar un conjunt de sitges $\mathrm{i}$ altres estructures, vinculades a un assentament rural relacionat amb l'explotació agrícola d'aquest sector de l'ager Tarraconensis, que va funcionar durant un període datat entre l'època tardorepublicana i final del segle I dC.

Paraules clau: Sitjar, producció de cereals, ager Tarraconensis, període ibèric tardà, època romana tardorepublicana, Alt Imperi.
A preventive archaeological excavation carried out in 2014 at the locality of El Vendrell brought to light several silos and other features associated with an agricultural settlement of this sector of Ager Tarraconensis. The site is dated between the period of the Roman Republic and the late 1st century AD.

Keywords: silo, cereal production, Ager Tarraconensis, Late Iberian period, Roman Republic, Early Roman Empire. 


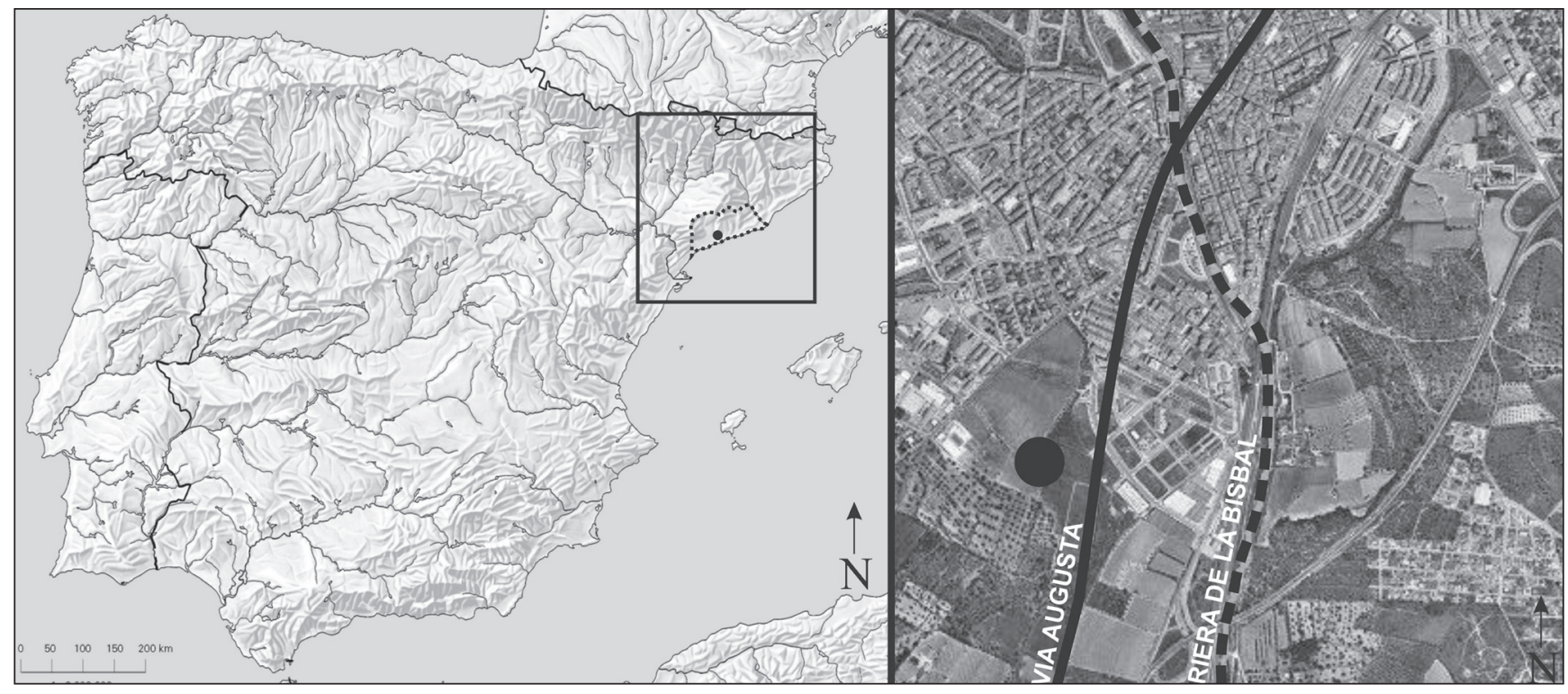

Figura 1. Situació del jaciment (punt negre). A l'esquerra, el jaciment de la Devesa dins dels límits de l'ager Tarraconensis (línia discontínua). A la dreta, el jaciment de la Devesa amb relació a la Via Augusta i a la riera de la Bisbal.

\section{Introducció}

Entre els mesos d'agost i setembre del 2014 es va portar a terme una petita excavació arqueològica al jaciment de la Devesa/el Quartei, a l'extrem sud del nucli urbà del Vendrell (Baix Penedès). Aquesta intervenció preventiva va ser motivada pel fet que la delimitació arqueològica associada als treballs d'urbanització del sector S-16 "Les Deveses", Pla Parcial "Can Cerdanyès", va donar resultats positius. Així, una part molt concreta dels terrenys a urbanitzar restà com a zona d'interès arqueològic i posteriorment, ja durant l'execució dels treballs d'urbanització, es va realitzar l'excavació arqueològica que ha proporcionat les dades que presentem en aquest article. ${ }^{1}$

Això no obstant, hem de lamentar que la intervenció es va limitar a la zona afectada per un dels vials de la nova urbanització, i no a tota l'àrea del jaciment definida durant la delimitació prèvia. Amb tot, cal remarcar que un altre fet, aliè a la direcció arqueològica, va provocar que en varis punts de la zona intervinguda s'haguessin d'aturar els treballs abans de finalitzar-ne la corresponent documentació estratigràfica. Això va fer que en alguns casos no es pogués arribar a documentar de manera satisfactòria les dimensions i la possible funcionalitat de les estructures exhumades, i que tampoc puguem confirmar o desmentir l'existència de més restes en els punts on no vam poder intervenir.

Les restes que ara passarem a descriure de manera acurada, corresponen a un assentament rural relacionat molt probablement amb l'explotació agrícola d'aquest

1. L'excavació arqueològica va ser dirigida per Josep Francesc Roig Pérez. La delimitació, realitzada entre el 9 i 18 d'abril del 2008, va anar a càrrec de César Augusto Pociña López, en col-laboració d'Inmaculada Mesas Torronteras, tots de l'empresa CODEX - Arqueologia i Patrimoni. sector de l'ager Tarraconensis en un període molt concret, que va des de l'època tardorepublicana fins a final del segle $\mathrm{I} \mathrm{dC}$, quan sembla que s'abandonà de manera definitiva.

\section{Context geogràfic i històric}

La part de jaciment excavat se situava dins d'uns camps de vinya, entre el camí de Sant Vicenç de Calders al Vendrell i el camí ral, traçat que coincideix amb la Via Augusta ${ }^{2}$ (figura 1). Concretament, l'excavació es va dur a terme a una vuitantena de metres al sud de la masia de Can Cerdanyès, situada en un pla amb petits desnivells que són salvats amb marges de pedra seca.

Aquesta plana litoral és constituïda per un miocènic residual, cobert per dipòsits al-luvials quaternaris que proporcionen unes terres riques per al conreu, i regada per petits barrancs de cabal intermitent, sovint torrencial, típics del clima mediterrani, com ara la riera de la Bisbal. ${ }^{3}$ En definitiva, uns condicionants que han facilitat, ja des d'antic, l'establiment de diferents grups humans (Asensio et al. 1996: 58).

La primera notícia que es té del jaciment data del 1948, i fou recollida per J. Solé Caralt, qui mencionava restes d'un tram de via en aquesta finca, a més de la troballa d'un mil.liari (Solé 1952). Amb posterioritat i prèviament a la nostra actuació, aquesta zona havia estat objecte de diferents prospeccions arqueològiques, a càrrec tant del Museu Arqueològic del Vendrell (1997) com de l'Institut d'Estudis Catalans (1999), i també d'una delimitació l'any 2008 (Codex 2008), que va confirmar l'existència de restes arqueològiques.

2. Situada uns 340 metres al sud-est.

3. Curs d'aigua, però també via de comunicació vers l'interior. 


\section{El jaciment}

Com ja hem apuntat en el capítol introductori, la nostra intervenció es va limitar a l'espai inclòs dins dels límits d'un dels vials associats a la urbanització projectada, i va permetre identificar un conjunt d'estructures en una àrea total de $470 \mathrm{~m}^{2} \mathrm{i}$ amb una cronologia que va des del darrer quart del segle II aC fins al darrer terç del segle i dC.

Les restes estructurals conservades es trobaven, la gran majoria, en un estat força deficient, a causa de la poca consistència dels materials i sobretot dels treballs agrícoles d'època contemporània (llaurada i espoli). La totalitat de les estructures documentades corresponien a fonamentacions de murs no conservats $i$ a estructures negatives (les millor conservades), concretament sitges d'emmagatzematge excavades al subsòl (figures 2-4).

Pel que respecta a l'estratigrafia documentada, a part dels diferents nivells de terra identificats a l'interior de les sitges, la intervenció arqueològica va permetre excavar tan sols tres estrats de terra d'interès patrimonial: un nivell de regularització datat als segles II-I $\mathrm{aC},{ }^{4}$ un nivell de terraplenament amb una cronologia centrada en la primera meitat del segle I $\mathrm{dC}^{5}$ i un nivell de rebliment que hem datat a mitjan segle I dC. ${ }^{6}$

\section{El sitjar de la Devesa}

Les sitges documentades durant la nostra intervenció formaven part d'un sitjar o camp de sitges el número de les quals no es pot determinar, per les causes ja mencionades anteriorment. En total vam poder identificar deu sitges, concentrades a l'extrem occidental en un espai de $290 \mathrm{~m}^{2}$, amb l'excepció d'una que es trobava en la zona centre-meridional, separada de les altres uns 14 metres. Val a dir també que dues tan sols van poder ser documentades únicament a nivell de planta superficial. ${ }^{7}$

Totes elles foren excavades al substrat geològic tipus tapàs ${ }^{8}$ (figura 4), i un cop finalitzada la seva funció primària d'emmagatzematge de cereals, foren aprofitades com a abocadors de deixalles domèstiques, si bé l'estudi del material que les amortitza ens indica que aquest procés va ser dilatat en el temps, i que algunes van romandre en ús, almenys algun temps, quan es van construir les edificacions de les fases $2 \mathrm{i}$ 3. A més, tot i que es trobaven en molt bon estat de conservació, cal dir que només una es conservava de forma íntegra, ${ }^{9}$ ja que la resta tenien la part superior de les boqueres escapçada.

Quant a la morfologia, segons la seva secció hem identificat sis sitges de perfil globular, una de perfil pseudoglobular amb boca el-líptica, i una altra de

4. Codificat com UE 3012 .

5. Codificat com UE 3019.

6. Codificat a la memòria d'excavació com la UE 3002.

7. Les codificades com UE 3051 i 3053, que no van ser excavades per motius aliens a la direcció arqueològica.

8. Compost d'argila de color taronja i gravetes carbonatades, així com altres materials silicis propis d'un ambient humit.

9. La sitja codificada com UE 3032. secció cilíndrica i boca també cilíndrica. En tots els casos presenten el fons pla, i, tret de la conservada íntegrament, de la resta a tan sols en tres ${ }^{10}$ es va poder documentar el cobertí (llosa de pedra) caigut al seu interior.

Abans de centrar-nos a descriure les sitges, llur contingut i el moment d'amortització, hem de fer esment de la presència, en el seu entorn, d'una capa de terra estesa a tall de regularització del terreny natural. Aquest estrat ${ }^{11}$ contenia un conjunt de materials (figura 5) entre els quals destaquen importacions d'àmfores de l'àmbit púnic, tant ebusitanes com del Cercle de l'Estret i centre-mediterrànies, aquestes últimes amb dos exemplars de tripolitana antiga. De la Itàlia tirrènica vam recuperar almenys dos exemplars d'àmfora grecoitàlica, de les quals tenim una vora del tipus bd2 del Dicocer que conserva un segell en cartel.la rectangular de $33 \times 16 \mathrm{~mm}$ on es pot llegir una "A...", dintre de la qual l'espai només permetria la impressió d'una altra lletra, que no es conserva (figures 5,1 i 14,1). Pel que fa a la vaixella fina, tan sols vam documentar fragments de vernís negre napolità del tipus Campaniana $\mathrm{A}$ mitja, present en les copes Lamb. $27 \mathrm{Ba} / \mathrm{F} 2843$ i 27Bb/F 2823, així com un fons amb restes de decoració impresa amb palmeta. Es completa el context de materials amb les produccions indígenes, concretament àmfores, ceràmica comuna llisa i pintada, i olles en ceràmica grollera de cuina ibèrica. Entre la vaixella de taula trobem gerretes, una copa i una pàtera, acompanyada de tenalles i olles d'emmagatzematge. Tot plegat conforma un conjunt ceràmic que podem datar al llarg del segle II $\mathrm{aC}$, com ens estaria indicant la presència de les àmfores grecoitàliques, si bé les copes de vernís negre de la producció A mitja ja ens centren la cronologia del conjunt al període 180-100 aC (Vivar 2005: 26). La resta de material, bàsicament la ceràmica comuna ibèrica, no ens permet precisar aquesta cronologia. Per contra, sí que hem de fer esment dels dos exemplars de tripolitana antiga, que si bé ja es comencen a produir a inici del segle II aC, la seva presència als nostres jaciments no es començarà a notar de manera destacada fins a la caiguda de Carthago, quan es produeix un ressorgiment comercial d'altres ciutats nord-africanes que, d'alguna manera, es beneficien del seu nou estatus arran de la conquesta romana (Ramon Torres 2008: 69). De fet, a la capital de la Citerior, Tàrraco, apareixen per primer cop en contextos del tercer quart del segle II aC, i la seva presència s'incrementa notablement, a nivell quantitatiu, durant la centúria següent (Díaz en premsa). Per aquestes raons, i malgrat l'escassetat de material amb una cronologia precisa, creiem poder datar aquest estrat i, per tant, aquesta fase, al llarg de la segona meitat del segle ir aC. 


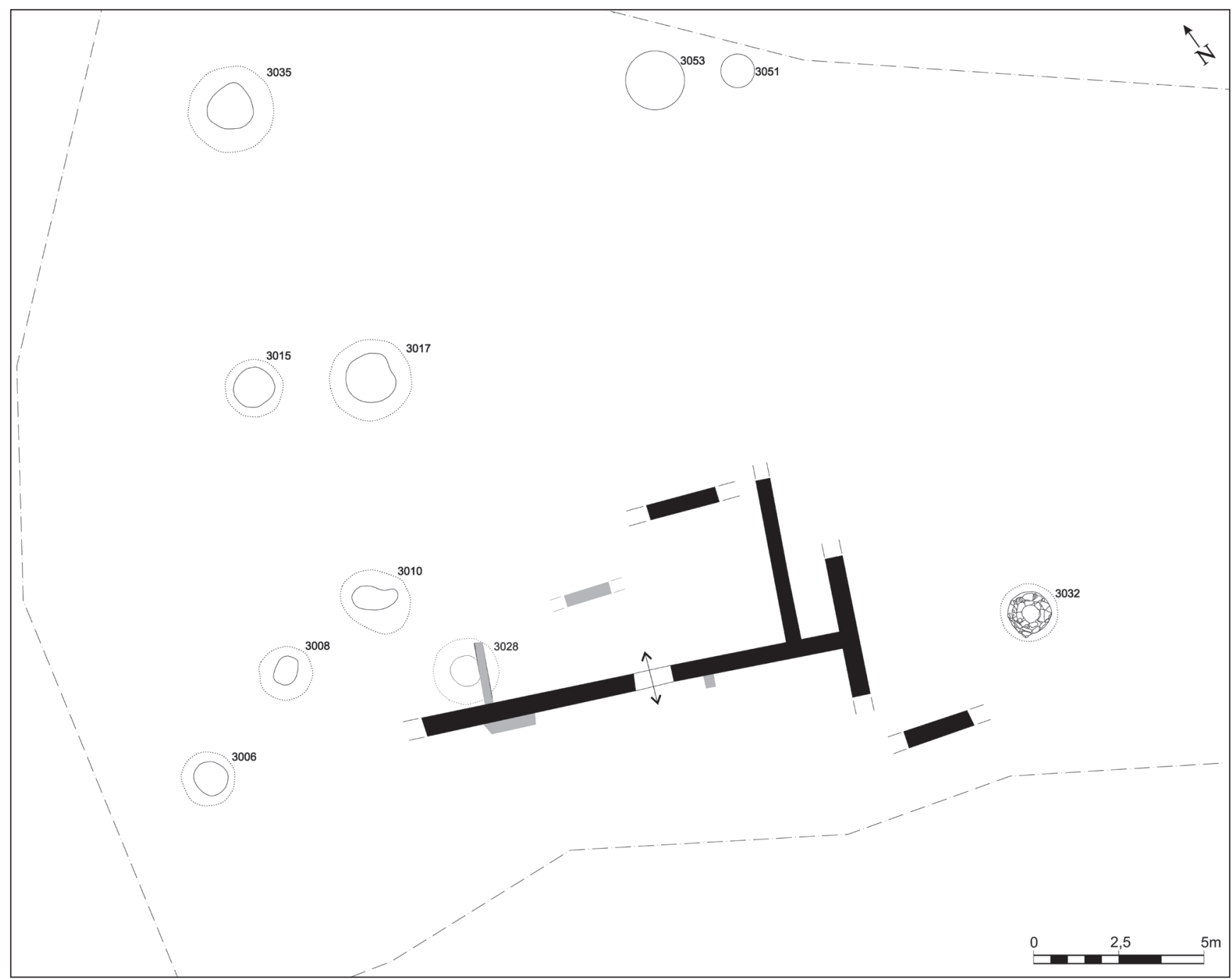

Figura 2. Planta general de les restes documentades. En color gris, les corresponents a la fase 2 i en color negre, les de la fase 3 .

\section{L'anul.lació de les primeres sitges i les evidències de la segona fase ocupacional: les primeres construccions}

En aquest moment, tres de les sitges excavades van ser anul.lades i es van utilitzar com a abocadors de residus. No podem determinar si aquesta anul-lació va venir condicionada pel nou projecte d'ocupació del sector, o bé va respondre a un procés de colgament més o menys prolongat en el temps. El que sí hem pogut comprovar és que la sitja 3028 i probablement, també la 3032, quedaven afectades per la construcció de murs que hi passaven per sobre i les inutilitzaven (figura 2).

Es tracta d'un conjunt de quatre fonamentacions ${ }^{12}$ obrades en maçoneria de pedres calcàries locals mitjanes lligades amb argila, i amb una amplada mitjana de 0,40 metres en els casos millor conservats. Hem de dir que aquests fonaments es trobaven molt arrasats, a causa de l'acció destructiva dels treballs agrícoles moderns i contemporanis, en forma de rases de vinya, i també per les reformes de la fase 3, fet que ens ha impedit definir les característiques funcionals i arquitectòniques del conjunt. Tot i així, el conjunt que formen totes quatre estructures ens dibuixen una planta rectangular de 6,2 metres de llarg per 3 metres d'amplada i una superfície hipotètica entorn els $19 \mathrm{~m}^{2}$ (figura 2, en gris i figura 3,3).

Respecte a la data de construcció, com que van ser construïdes tallant directament el substrat natural, l'únic element que ens ofereix una datació aproximada és el material provinent de les sitges anul-lades per tal d'erigir aquests murs, ${ }^{13}$ ja que estratigràficament estableix el terminus post quem. Aquest material forma un conjunt de 6.431 fragments de diversa índole, entre els quals tenim restes de materials lítics, fauna i un conjunt ceràmic compost per 5.920 fragments, dels quals hem pogut definir un conjunt de vaixella formada per un NMI de 222, que tot seguit passem a descriure. 


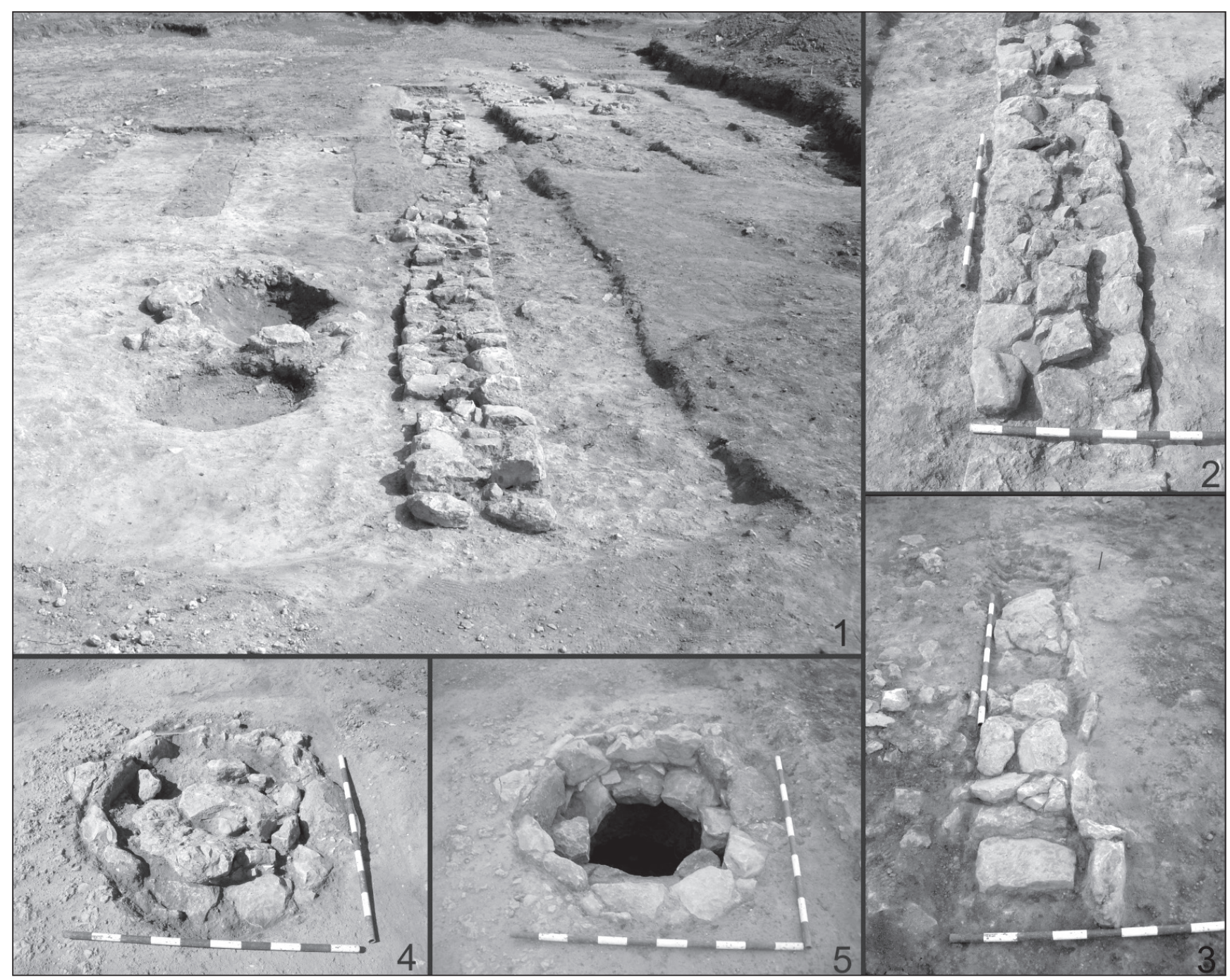

Figura 3. Recull d'imatges significatives: 1. General del jaciment amb orientació oest-est. 2. Fonamentació de la fase 3 UE 3021, detall de la tècnica constructiva. 3. General de la fonamentació de la fase 2 UE 3031, amb orientació est-oest. 4. General de la sitja UE 3032 abans d'extreure'n el cobertí UE 3033, amb orientació est-oest. 5. General de la sitja UE 3032 un cop desmuntat el cobertí. Observem el muret perimetral UE 3039, amb orientació est-oest.

\section{Sitja 3010}

Aquesta sitja, que conservava una profunditat màxima de $2,5 \mathrm{~m}$, estava reblerta per dos estrats de terra, que són els que han proporcionat els contextos més nombrosos entre totes les sitges. El nivell inferior $^{14}$ era una capa de terra solta de color gris, amb presència de pedres calcàries irregulars i un conjunt de materials que ascendeix a 1.109 fragments. 285 corresponen a restes animals, 23 són fragments de metall, entre els quals destaca una clau de porta de ferro, i 9 peces lítiques, entre les quals trobem un molí de barca, diverses mans de molí, un morter i vàries pedres de polir.

Pel que respecta al conjunt ceràmic, d'una banda tenim elements com ara pondera i fusaioles, i, de l'altra, un conjunt vascular força interessant (figura 5). Començant pel grup de les àmfores, les més nombroses són les de tradició ibèrica, si bé tenim constància d'importacions púniques del Cercle de
l'Estret, massaliotes, i un exemplar de grecoitàlica clàssica del tipus bd 2 i un altre d'ebusità del tipus PE 17/T-8.1.3.2. Dins de vaixella fina, tenim gobelets en grisa de la costa, de producció local o regional, i vasos de vernís negre de diversos tallers, com ara els napolitans de la Campaniana A, amb formes de la A antiga com el plat de peix Lamb. 23/F 1121, i ja de la producció mitjana copes M. 68bc/F 3131 i els bols Lamb. 27ab/F2784, a més d'altres copes i/o bols, la tipologia dels quals no s'ha pogut definir. ${ }^{15}$ També hem documentat un altre plat de peix tipus Lamb. 23/F 1120 de producció etrusc-lacial, i provinent de tallers itàlics no identificats, un gobelet del tipus F 7222, molt similar als de la forma Mayet 2 de parets fines. Ja passant al grup de la ceràmica comuna, hem de destacar el domini de la vaixella ibèrica en el repertori de taula, tant llisa com pintada, amb presència de copes i gots bicònics, junt amb la qual trobem dues copes de ceràmica comu- 
na de procedència eivissenca. Cal enumerar també, dins de la vaixella de cuina, olles i tapadores grolleres de producció local o regional.

El segon nivell de colgament, en el procés formatiu, era una capa de terra solta de color marró fosc barrejat amb carbonets i pedres irregulars, ${ }^{16}$ de la qual es va recuperar un conjunt de materials format per 2.568 fragments, dels quals 18 eren restes d'animals, 1 corresponia a una agulla de cosir a mig treballar feta en os, i la resta -2.549- eren fragments ceràmics (figura 6). Entre les peces ceràmiques hem documentat material constructiu de tipus romà, com tegulae i imbrices. Entre la vaixella recuperada destaquen, pel seu alt nombre, les àmfores ibèriques, si bé també hi són presents les importacions itàliques, tant de la franja adriàtica amb un envàs de Bríndisi, com de la vessant tirrènica, d'on provenen envasos del tipus grecoitàlic i de tres variants de la Dr. 1. Aquest conjunt es completa amb envasos púnics procedents del Cercle de l'Estret i també del nord d'Àfrica, concretament una àmfora tripolitana antiga. Respecte al grup de la vaixella fina, el repertori és força reduït, amb dues copes i una pàtera Lamb. 5 de la Campaniana A, un got Lamb. 3/F 7540-50 de la Campaniana B de Cales i un gobelet de parets fines Mayet 2D. També es va recuperar una llàntia i un conjunt de ceràmica comuna entre la qual predominaven, com és habitual, les produccions ibèriques. De la vaixella de taula hem documentat copes, gots i alguna peça de tipologia indeterminada i decoració pintada de producció ibèrica. Hem d'afegir també tenalles per a l'emmagatzematge d'aliments, a més d'un contenidor de tipologia romana -dolium- del qual també es va recuperar la tapadora. Finalment, ens hem de referir a la ceràmica de cuina, on trobem recipients de la ceràmica grollera ibèrica com ara olles $\mathrm{i}$ tapadores, juntament amb un exemplar de cassola de cuina itàlica de la forma Vegas 14, i també altres fragments informes de ceràmica comuna eivissenca.

\section{Sitja 3028}

Aquesta sitja, amb una secció que arribava als 2,3 m de profunditat, estava colgada per un estrat de terra solta, de color marró clar, ${ }^{17}$ barrejat amb una gran quantitat de pedres calcàries irregulars. El conjunt de materials que es va recuperar de l'excavació del seu farciment estava format per 808 fragments, dels quals 4 pertanyien a restes animals i la resta a ceràmica (figura 6). El conjunt de les àmfores estava dominat pels envasos de tradició ibèrica, si bé també detectàrem la presència de, com a mínim, un contenidor procedent del Cercle de l'Estret i una àmfora eivissenca del tipus PE 15/T-8.1.2.1, que té una datació que abraça de final del IV aC a un moment indeterminat del segle III aC. No vam documentar cap fragment de vaixella fina. Entre la ceràmica comuna destaca el domini de les produccions locals de tradició ibèrica, amb vaixella llisa representada per gerretes, copes i tenalles, i també un plat de la ibèrica pintada. Es completa el grup amb vaixella de cuina de la pro-

16. Codificat com UE 3011.

17. Codificat com UE 3029. ducció grollera ibèrica, de la qual tenim una olla i una cassola baixa. Finalment, hem de fer esment de la presència d'un tap o petita tapadora, feta amb un fragment de ceràmica retallat circularment, i com en el cas anterior, material constructiu amb peces de tovots i d'imbrices.

\section{Sitja 3032}

Es tracta de l'única sitja que conservava la seva secció completa, arribant als 2,8 metres de fondària. La boquera estava rematada per un muret de maçoneria de pedres irregulars i argila, ${ }^{18}$ sobre la qual se situava el cobertí, una llosa de calcària local ${ }^{19}$ d'uns 0,60 metres de diàmetre (figures 3 i 4,1).

Al seu interior vam documentar un total de tres estrats (figura 7): l'inferior ${ }^{20}$ era un nivell de terra $\mathrm{i}$ arenes de textura solta $\mathrm{i}$ color gris, amb presència de carbonets, alguna pedra calcària local sense treballar i una gran quantitat de ceràmica. Per sobre es va documentar una capa de terra solta de color marró i gris, ${ }^{21}$ i finalment l'estrat superior, de terra de matriu argilosa. ${ }^{22}$

El primer estrat de colgament en la seqüència formativa va proporcionar un conjunt de 1.369 peces, de les quals la immensa majoria eren fragments ceràmics -1364 - i tan sols 5 fragments de fauna. Entre la vaixella recuperada destaca la presència d'àmfores ibèriques, amb les quals trobem importacions púniques del Cercle de l'Estret i itàliques, de les quals hem identificat envasos del tipus grecoitàlic i Dr. 1B. Entre la vaixella fina hem de mencionar la troballa d'un peu de copa de la producció Campaniana A, i ja dins el grup de la ceràmica comuna tenim, sempre de producció ibèrica, copes i gerres llises, i de la producció pintada tapadores i tenalles.

El segon estrat del procés de colgament d'aquesta sitja va proporcionar un total de 266 objectes, de les quals 14 eren restes animals, 251 fragments ceràmics, i 1 possible pes de pedra calcària. Quant a la ceràmica recuperada, trobem importacions d'àmfores ebusitanes, massaliotes, del Cercle de l'Estret i del tipus grecoitàlic bd3. A més, entre la vaixella comuna, de producció ibèrica, tenim tenalles de la producció llisa i càlats i gobelets de decoració pintada.

Lestrat que ocupava la part superior de la sitja estava compost per un conjunt de 311 peces, de les quals 151 eren restes animals i la resta, 160, fragments de ceràmica. De tot el conjunt hem de fer esment del grup de les àmfores, on s'identificà un NMI de 7 , amb ibèriques de boca plana, grecoitàliques clàssiques i peces indeterminades de producció púnica d'Eivissa i del Cercle de l'Estret, a més d'algun exemplar de procedència desconeguda. Es completa el conjunt amb

18. Un fet comú és el de reforçar les parts més febles de les sitges, com ara els colls i les boqueres, segons ha documentat J. Miret (2005: 327).

19. De fet, la pedra emprada com a material constructiu en el jaciment és tota la mateixa: pedres calcàries locals, en alguns casos treballades o desbastades i en altres sense manipulació o treball antròpic.

20. Codificat com UE 3041.

21. Codificat com UE 3040.

22. Codificat com UE 3034. 


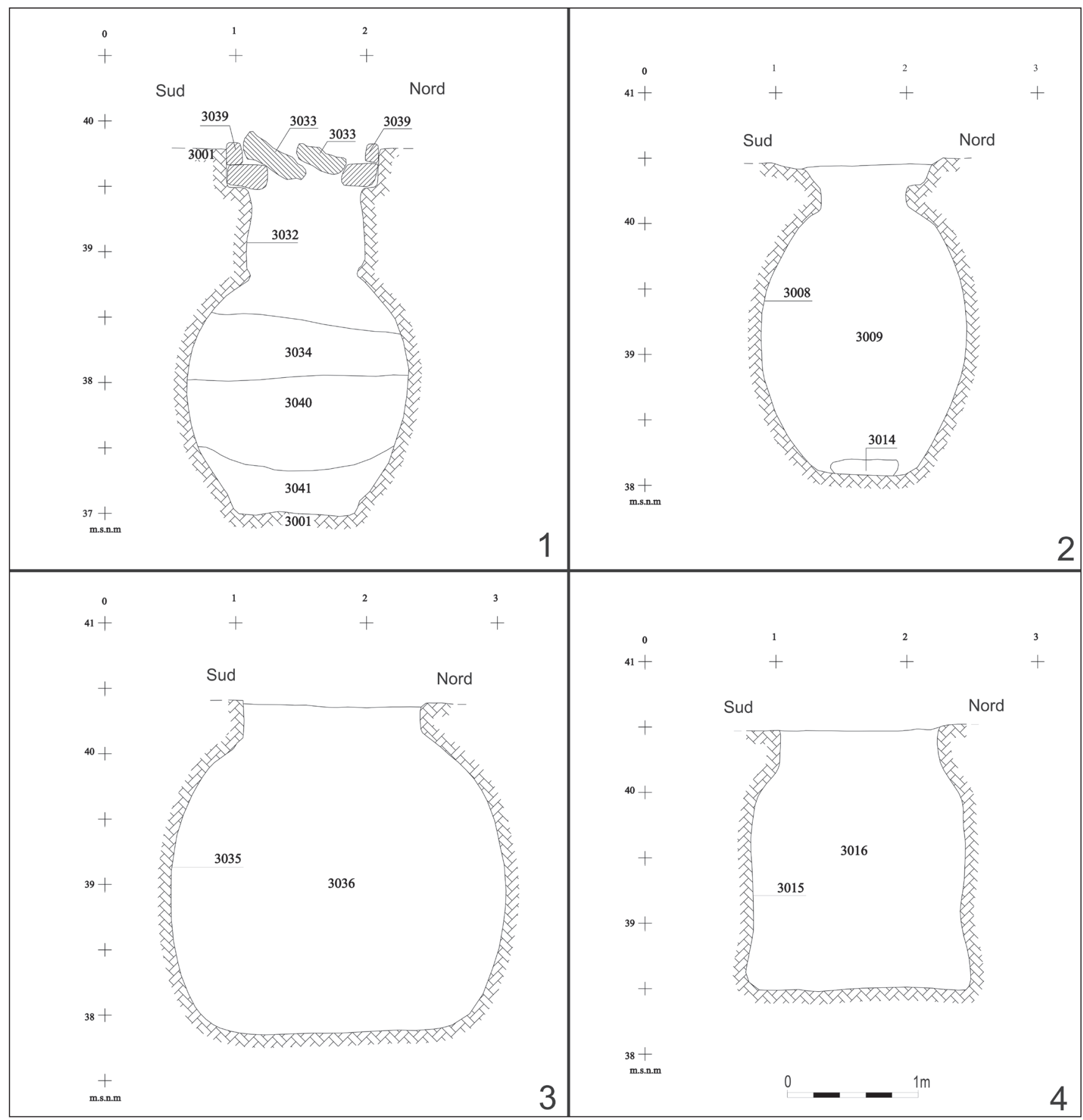

Figura 4. Recull de seccions significatives de les sitges excavades: 1. Sitja UE 3032 (reblerta durant la fase 2). 2. Sitja UE 3008 (reblerta durant la fase 3). 3. Sitja UE 3035 (reblerta durant la fase 3). 4. Sitja UE 3015 (reblerta durant la darrera fase).

la ceràmica comuna, de la qual tenim produccions ibèriques llises i pintades, en què destaca algun càlat i una cassola pertanyent a la producció ibèrica de cuina en ceràmica grollera.

Respecte a les qüestions cronològiques, no podem fer gaires precisions a causa de la poca representativitat de materials significatius. Es tracta d'un conjunt de peces pròpies del període tardorepublicà, que inicialment podríem datar en el segle II aC, arran de la presència d'àmfores grecoitàliques clàssiques juntament amb les produccions de Campaniana A d'aquest moment, però la troballa d'un contenidor itàlic del tipus Dr. 1B ens situa el rebliment d'aquesta sitja, almenys, en els primers anys del segle I aC.

Com ja hem indicat, el moment en què datem l'amortització d'aquestes sitges l'hem de situar al llarg del segle I aC, ja que si bé tenim vaixella pròpia de tot el període tardorepublicà, des de final del segle III $\mathrm{aC}$, com ara les produccions ibèriques entre les quals tenim els càlats o la vaixella de vernís negre amb formes com el plat de peix Lamb. 23 o la copa Morel 68 bc, també trobem produccions pròpies de moments més avançats del segle II aC, com són els vasos de la Campaniana B de Cales presents amb la 


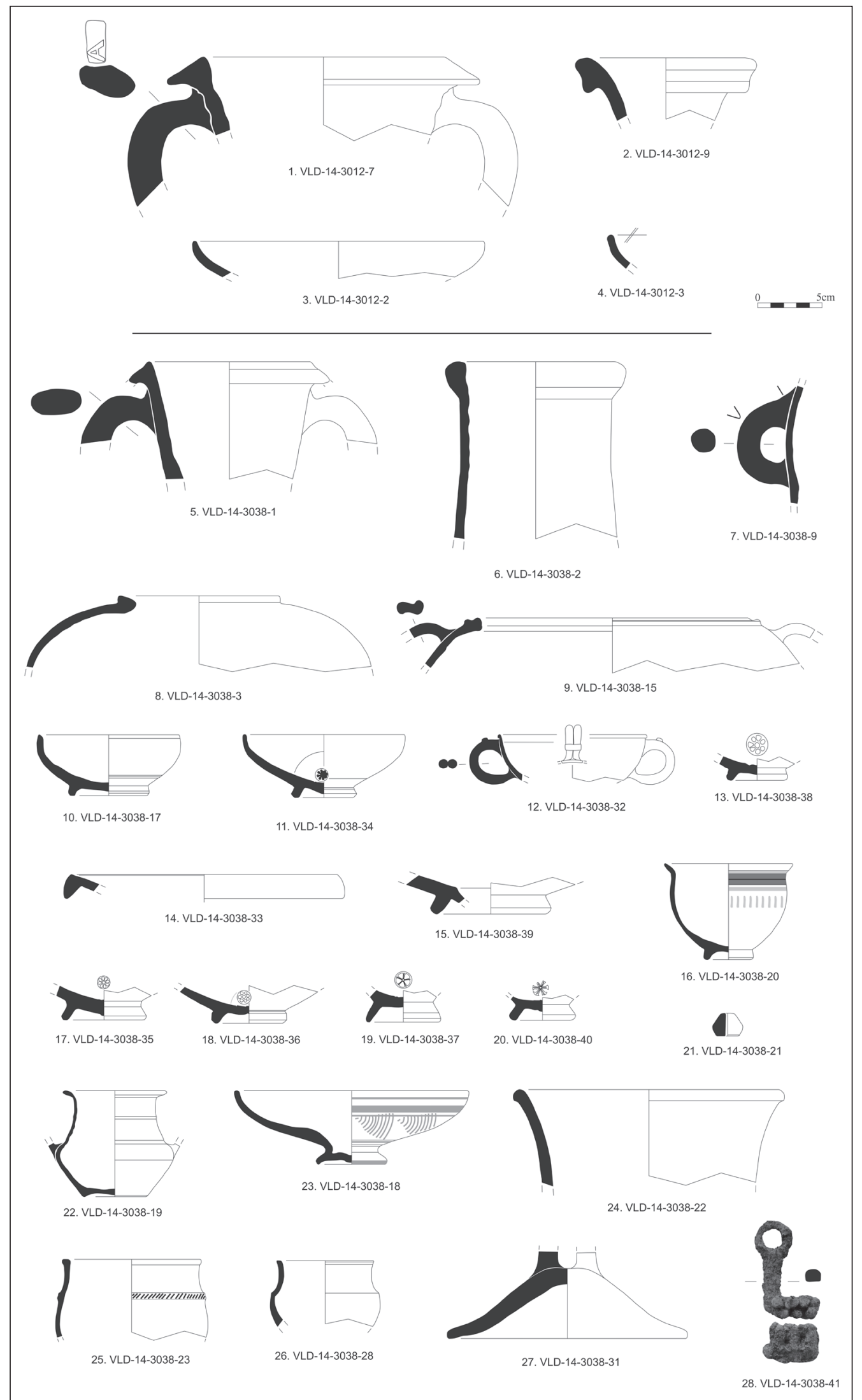

Figura 5. Material significatiu de les UE 3012 i 3038. 1. Àmfora grecoitàlica bd2 amb segell rectangular "A...”. 2. Àmfora tripolitana antiga. 3. Campaniana A F2823/Lamb. 27Bb. 4. Campaniana A F2843/Lamb. 27Ba. 5. Àmfora grecoitàlica bd2. 6. Àmfora PE 17/T-8.1.3.2. 7. Àmfora ibèrica, ansa amb incisió i V en relleu ante cocturam. 8. Àmfora ibèrica. 9. Comuna oxidada ibèrica, tenalla. 10. Comuna oxidada púnico-ebusitana, copa. 11. Campaniana A mitja, F2784/Lamb. 27 ab. 12.

Campaniana A antiga, F3131/M68bc. 13. Campaniana A mitja, copa/bol amb roseta central. 14. Campaniana A antiga, F1121/ Lamb. 23. 15. Vernís negre etrusc-lacial, F1120/Lamb. 23. 16. Vernís negre indeterminat, F2222 (engalba metàl-lic i decoració de línies paral-leles en blanc i vermell). 17-19. Campaniana A mitja, copa/bol amb roseta central. 20. Vernís negre etrusclacial amb roseta central. 21. Fusaiola. 22. Grisa de la costa catalana, gobelet ansat. 23. Comuna oxidada pintada ibèrica, tapadora. 24 i 25. Grollera oxidada ibèrica, olles de cocció. 26. Comuna oxidada a mà, olleta. 27. Comuna oxidada a mà, tapadora. 28. Clau de porta, de ferro. 


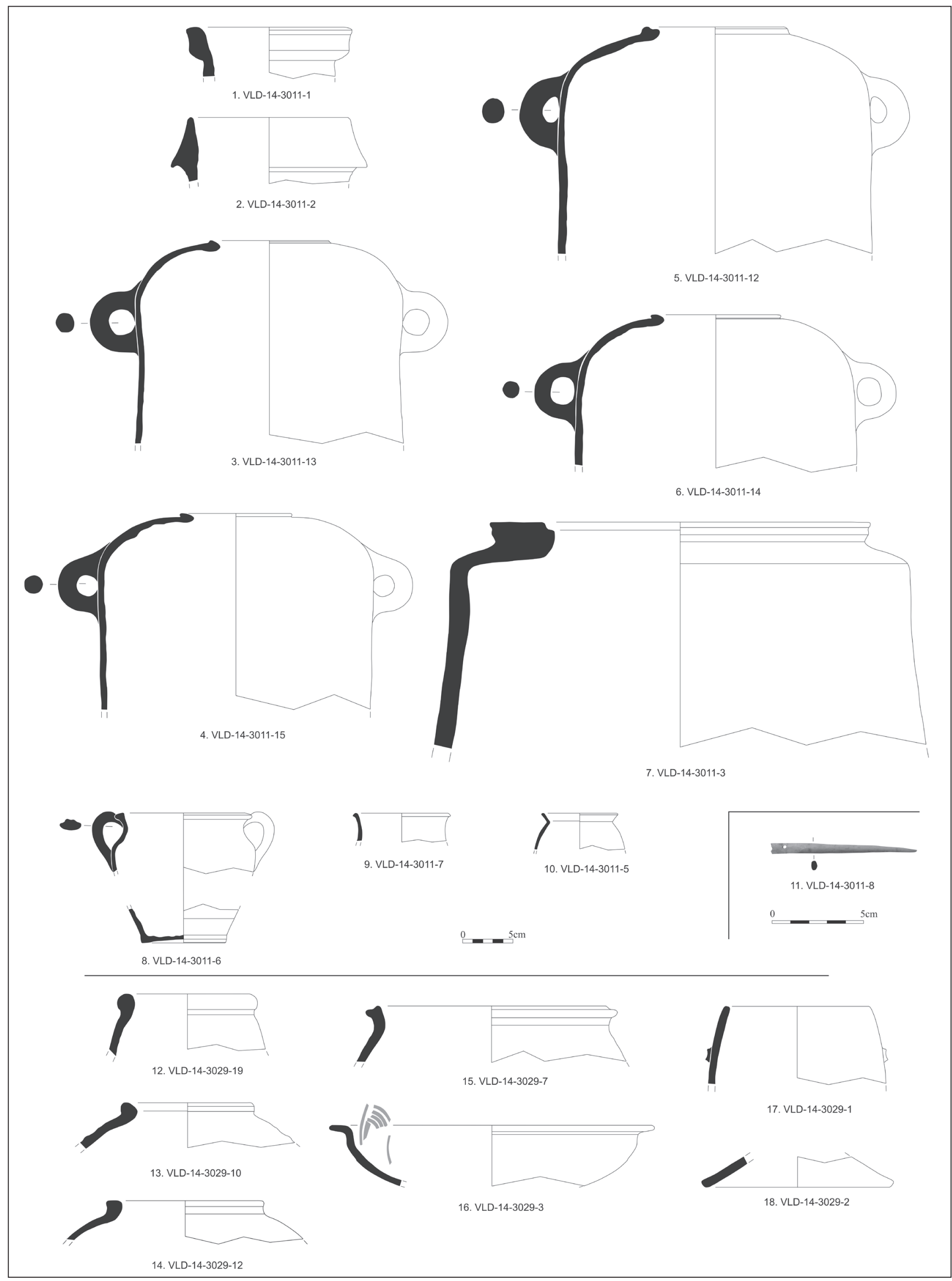

Figura 6. Material significatiu de les UE 3011 i 3029. 1. Àmfora tripolitana antiga. 2. Àmfora itàlica, Dr. 1C. 3-6. Àmfores ibèriques. 7. Dolium. 8. Grollera oxidada ibèrica, tenalla. 9. Campaniana B de Cales, F7540-7550/Lamb. 3. 10. Parets Fines, Mayet 2D. 11. Agulla de cosir en os. 12. Àmfora PE 15/T-8.1.2.1. 13 i 14. Àmfores ibèriques. 15. Comuna oxidada ibèrica, tenalla. 16. Comuna reduïda pintada ibèrica, plat. 17. Grollera reduïda ibèrica, olla de cocció. 18. Grollera oxidada ibèrica, tapadora. 


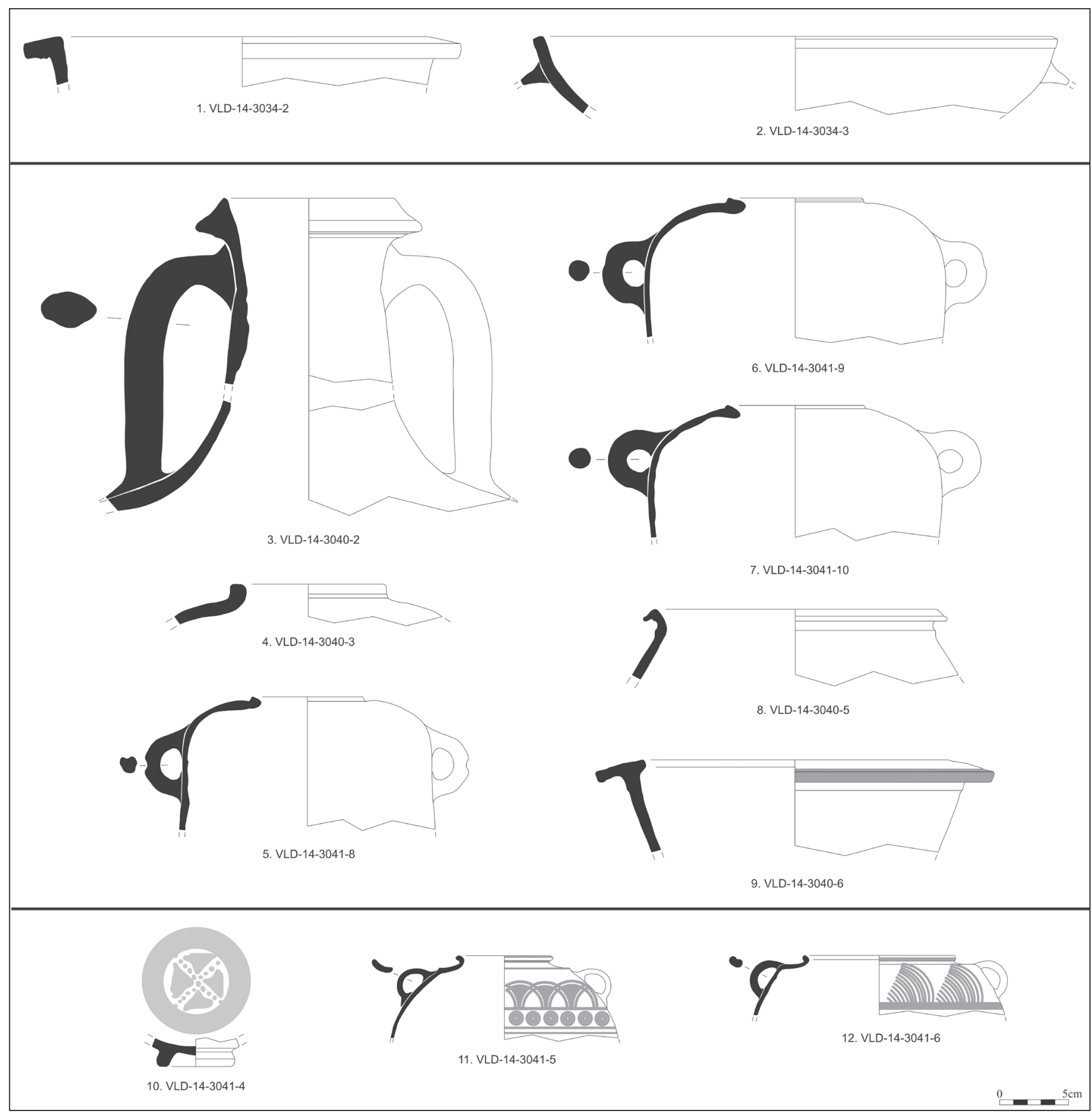

Figura 7. Material significatiu de les UE 3034, 3040 i 3041. 1. Comuna oxidada pintada ibèrica, càlat. 2. Grollera oxidada ibèrica, cassola. 3. Àmfora grecoitàlica bd3. 4-7. Àmfores ibèriques. 8. Comuna oxidada ibèrica, tenalla. 9. Comuna oxidada pintada ibèrica, càlat. 10. Campaniana A, copa. 11 i 12. Comuna oxidada pintada ibèrica, tenalles.

copa Lamb. 3 o les cassoles de cuina itàliques de la forma Vegas 14, a les quals s'afegeixen les àmfores produïdes a partir d'inici del darrer terç i el darrer quart del segle II $\mathrm{aC}$, les itàliques Dr. 1A i $1 \mathrm{C}$. Però la dada més destacada, en l'àmbit cronològic, és la presència de l'àmfora tripolitana antiga, que si bé ja es produeix durant tot el segle II aC, la seva exportació es veu intensificada a partir de mitjan d'aquesta centúria i la seva presència és més notable, en jaciments destacats com és el de Tàrraco, al llarg de tot el segle I aC (Díaz en premsa). Hi hem d'afegir també la presència d'un contenidor itàlic del tipus Dr. 1B, la producció del qual s'inicia a començament del segle I aC (Márquez, Molina 2005: 107). D’altra banda, la manca de materials que es puguin datar en un moment central o avançat del segle $\mathrm{I}$ aC ens podria ajudar a concretar la datació d'aquesta fase en la seva primera meitat, tot i que no ho podem confirmar amb seguretat.

\section{Les construccions de la tercera fase $i$ l'amortització del segon grup de sitges}

En un moment datat entre els inicis de la segona dècada del segle I dC i a mitjan centúria, es produeix una reforma que comportarà la destrucció i el desmuntatge fins a cota de fonament de les 


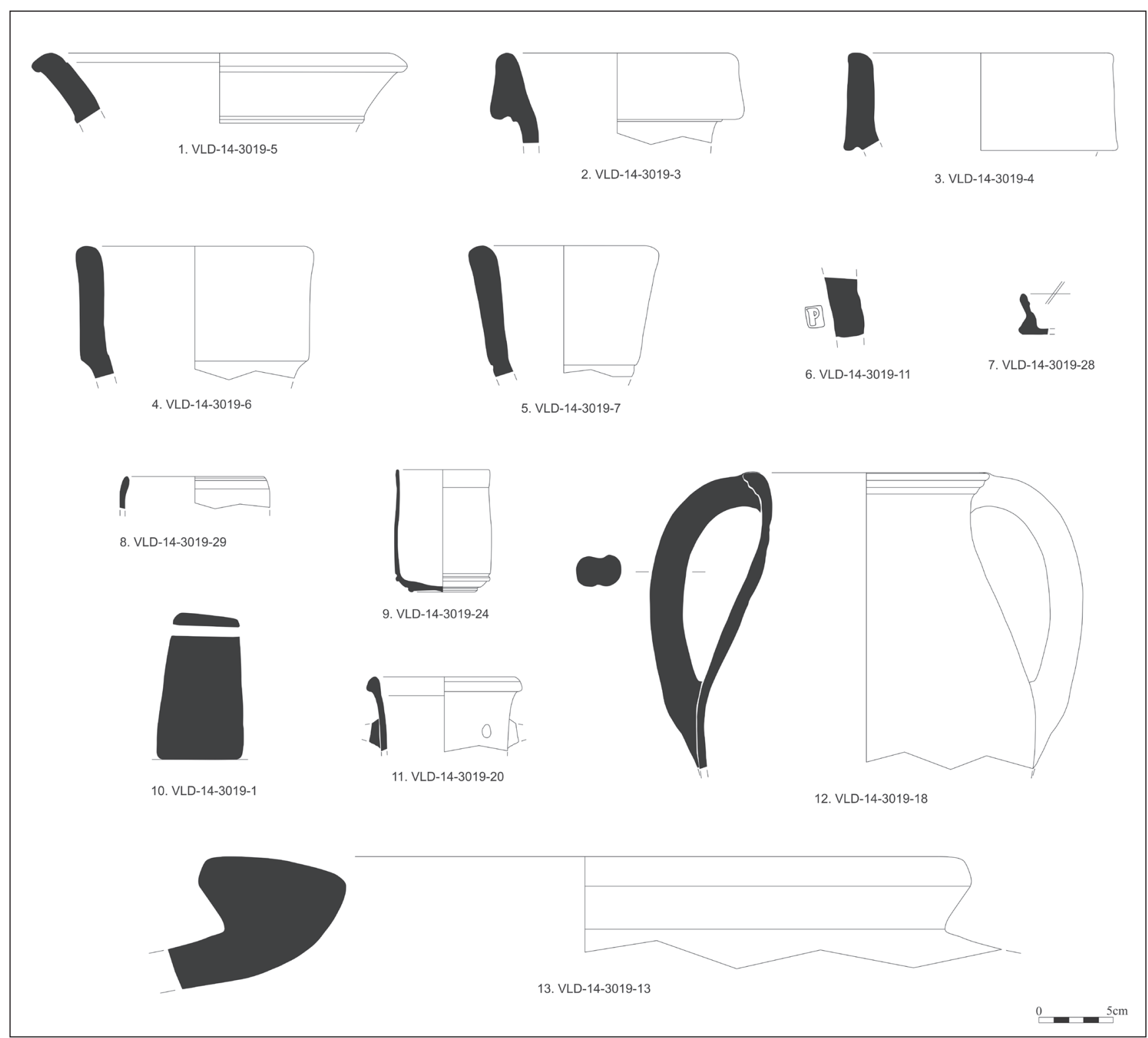

Figura 8. Material significatiu de la UE 3019. 1. Àmfora sud-hispànica, Dr. 7-11. 2. Àmfora itàlica, Dr. 1C. 3. Àmfora sudhispànica. Dr. 1B. 4 i 5. Àmfora tarraconense, Pascual 1. 6. Àmfora tarraconense, segell quadrangular "P". 7. TS itàlica, Consp. 18.2. 8. TS itàlica, Consp. 33.2. 9. Parets fines, Mayet 12. 10. Pondus. 11 i 12. Comuna oxidada, gerretes. 13. Dolium.

estructures de la fase prèvia, i l'extensió de nous nivells de regularització a tall de plataformes constructives. Es tracta de l'estrat codificat com UE 3019, que va proporcionar un conjunt ceràmic on trobem produccions pròpies de final del segle II i del segle I aC (figura 8), com ara les importacions d'àmfores itàliques $\mathrm{Dr}$. $1 \mathrm{~B}$, la pàtina de roig intern pompeià F3 Luni 1, una copa Lamb. 10 de la B de Cales i una llàntia Dr. 2, pròpies del segle $\mathrm{I} \mathrm{aC}$. Tot i així, el material més significatiu pertany a produccions més tardanes, característiques de la segona meitat d'aquesta centúria i que també es produeixen durant el segle I dC, com són les àmfores tarraconenses Pascual 1 i Oberaden 74, o les procedents de la Bètica, com són els contenidors de salaons Dr. 7-11, i una imitació de la forma Dr. 1C de les produccions de la Vall del Guadalquivir destinades a transportar vi. ${ }^{23}$ Cal destacar, en aquest punt, la recuperació d'un fragment informe, tal vegada pertanyent al coll, d'un exemplar d'àmfora procedent dels tallers del Camp de Tarragona, que conservava un segell estampillat amb la lletra $\mathrm{P}$ dintre d'una cartel.la quadrangular ${ }^{24}$ (figures 8,6 i 14,2), del qual tenim paral-lels en les produccions del Mas de Gomandí de Riudoms (Baix Camp) sobre àmfores Dr. 2-4 produïdes en aquest

23. A diferència de les imitacions de Dr. 1 gaditanes, que es destinaven a envasar salaons (García Vargas 1996; García Vargas 2001: 62; García Vargas et al. 2011; Sáez Romero 2008).

24. La cartel.la té unes mides de $15 \times 12 \mathrm{~mm}$. També s'han documentat exemplars d'àmfores Pascual 1 (a Sant Vicenç dels Horts, Baix Llobregat) i Dr. 2-4 (a Badalona, Barcelonès), però en el cas de les produccions de la costa central catalana, a diferència dels del Camp de Tarragona, els segells es troben als pivots de les àmfores (Berni 2015; Berni i Revilla 2008; Comas 1997). 
jaciment (Berni 2010: 190-191). En el grup de la vaixella de taula trobem parets fines formes Mayet 12 i Mayet 33, i les formes de TS Itàlica Consp. 12.2 i 18.2. Però finalment, les peces que ens indiquen la cronologia s'adscriuen a una producció que s'inicia ja a partir de final d'època augustal, com ara les parets fines Mayet 31 i 36, i la forma Consp. 22.5 de TS Itàlica, totes elles amb una cronologia inicial vers el $10 \mathrm{dC}$, i que poden arribar a mitjan segle en el cas de la terra sigil-lada mencionada, o al canvi de dinastia (vers el $70 \mathrm{dC}$ ) en el cas de les parets fines. No obstant això, l'absència de produccions que s'inicien en un moment més avançat, com ara les produccions sud-gàl-liques i hispàniques de terra sigillada o les primeres importacions de cuina africana, així com l'absència de contenidors de salaons bètics més evolucionats, tipus Beltrán 2, ens fan situar la datació d'aquesta fase entre els inicis de la segona dècada del segle I dC i mitjan centúria.

Quant a les característiques d'aquestes noves construccions, ${ }^{25}$ també molt afectades per les rases de vinya, identificàrem un àmbit arquitectònic del qual es conservaven els fonaments (figura 2 en negre i figura 3,1 i 2), també de maçoneria de pedres calcàries locals lligades amb argila, que presentaven una amplada que varia entre els 0,40 i els 0,55 metres.

Aquests fonaments ens definien un edifici de planta rectangular amb una superfície hipotètica entorn dels $54 \mathrm{~m}^{2}$, una llargada mínima de 12,5 per 4,7 metres d'amplada mínima i dotat d'una porta ${ }^{26}$ en un punt central del mur meridional. ${ }^{27}$ A l'extrem oriental, millor conservat, s'identificà un petit àmbit de planta rectangular de 4,3 per 1,25 metres que podia haver actuat com a passadís o corredor de distribució. En aquest mateix extrem oriental, però més al sud, s'identificà de forma molt puntual les restes d'una altra fonamentació. ${ }^{28} \mathrm{Cal}$ dir que la profunda alteració i arrasament de les estructures i estrats arqueològics ens impedeixen plantejar, per a aquest conjunt arquitectònic, interpretacions $\mathrm{i}$ atribucions funcionals més enllà de meres suposicions.

En canvi, cronològicament, sí que podem dir que molt probablement de manera coetània a la construcció d'aquestes noves edificacions, no sabem si com a pas previ o durant el període de construcció o del seu primer ús, es produí el colgament de quatre noves sitges.

El conjunt de materials recuperat d'aquestes sitges, i que detallem a continuació, està format per 3.741 fragments, entre els quals tenim restes de materials lítics, fauna i un conjunt ceràmic de 3.342 fragments, dels quals hem pogut definir un grup de vaixella formada per un NMI de 202.

25. Respecte a l'actual estat de les evidències que acabem de descriure, hem de dir que, per incompatibilitat amb el projecte urbanístic a executar, es desmuntaren de manera total o parcial alguns dels fonaments de maçoneria documentats, mentre que la resta foren protegits amb geotèxtil i arenes de gra fi, sempre seguint els paràmetres dictaminats pel Servei d'Arqueologia de la Generalitat.

26. Amb una llum de 0,94 metres.

27. Codificat com UE 3021.

28. Codificada com UE 3027.

\section{Sitja 3006}

Aquesta sitja tenia una fondària màxima conservada de 2,3 metres i es trobava farcida per un estrat de textura solta de color marró fosc amb taques grises. ${ }^{29}$ El material recuperat del seu interior es componia per un conjunt de 1.823 peces, de les quals 220 corresponien a restes d'animals, 6 fragments metàl.lics, dels quals en destaquen claus de ferro i un ham de pesca en bronze, i 2 peces pètries, concretament un molí de barca de granit i una mà de molí en pedra calcària.

Pel que respecta al conjunt ceràmic (figura 9), entre les importacions amfòriques tenim envasos púnics centre-mediterranis dels tipus T-7.5.2.2/Mañá C2c i tripolitana antiga, juntament amb contenidors de la itàlica tirrènica com ara els tipus Dr. 1A, 1C i grecoitàlica clàssica, i també adriàtics de producció brindisina. En destaquem també àmfores ibèriques de boca plana i un contenidor sud-hispànic del tipus Ovoide 2, una producció de la vall del Guadalquivir centrada a la segona meitat del segle i aC (García Vargas et al. 2011: 200), que presenta a l'ansa un segell conservat parcialment, del qual es pot llegir una "H..." dins una cartel.la rectangular ${ }^{30}$ (figures 9,3 i 14,3).

\section{Sitja 3008}

Aquesta sitja, de la qual es conservava una secció màxima de $2,3 \mathrm{~m}$ de fondària, estava reblerta per un únic estrat de terra, ${ }^{31}$ de textura solta i color marró fosc, amb presència de pedres calcàries heteromètriques i carbonets (figura 4,2). El conjunt de materials recuperats del seu interior el formaven un total de 176 peces (figura 10), de les quals 1 és un fragment de fauna, 1 és una peça de granit pertanyent a un catillus, i la resta són fragments ceràmics, amb diferents tipus de vaixella, material constructiu com ara tegulae i imbrices, i un pes de teler. Pel que respecta al repertori documentat, entre les àmfores trobem produccions locals ibèriques i d'altres d'importació ebusitana, bètica, itàlica de Bríndisi i de la regió tirrènica del tipus Dr. $1 \mathrm{~B}$, i també produccions catalanes del tipus Dr. 2B. La ceràmica comuna es caracteritza pel domini de les produccions ibèriques presents en vaixella de taula - tapadores, copes i gerretes-, i també d'emmagatzematge — tenalles_- El conjunt es completa amb algun fragment de ceràmica de cuina itàlica de forma indeterminada i també altres contenidors d'emmagatzematge de tipologia romana, com són els dolia, entre els quals hem de destacar un fragment de paret que conserva un grafit post cocturam, on es pot llegir la seva capacitat, “...XXX” (figures 10,5 i 14,12), i que hauríem de llegir [m()] XXX [s(extari)]. De fet, disposem de nombrosos exemples similars a l'àrea del Camp de Tarragona, recollits al treball de Piero Berni (Berni 2010).

Finalment, hem de fer esment de tapadores realitzades a partir de fragments de ceràmica retallats de manera circular.

29. Codificat com UE 3007.

30. Té una alçada de $12 \mathrm{~mm}$ i una longitud conservada de $15 \mathrm{~mm}$.

31. Codificat com UE 3009. 


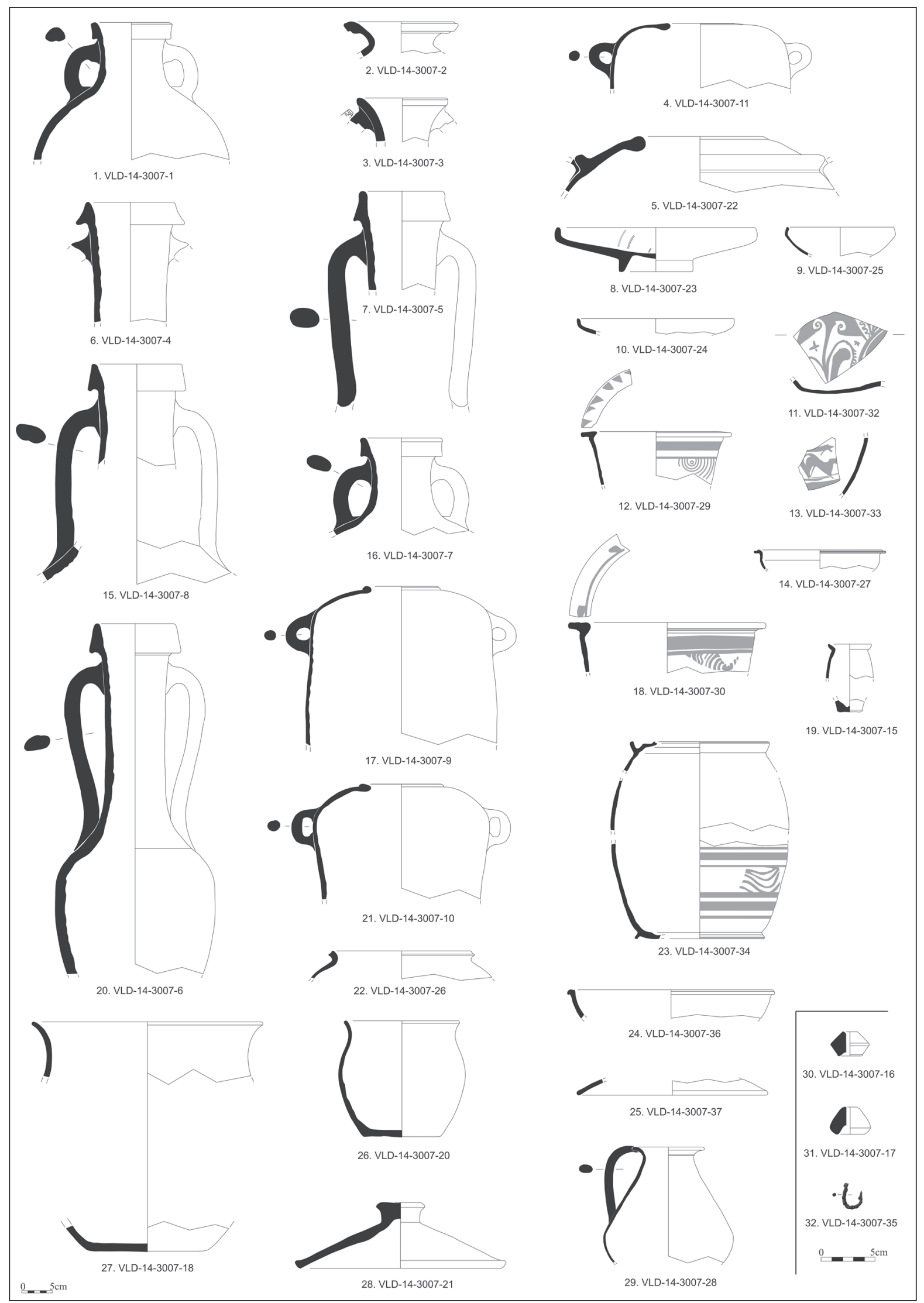

Figura 9. Material significatiu de la UE 3007. 1. Àmfora tripolitana antiga. 2. Àmfora púnico-ebusitana, T-7.5.2.2. 3. Àmfora sud-hispànica, Ovoide $2 \mathrm{amb}$ segell "H...". 4. Àmfora ibèrica. 5. Comuna oxidada ibèrica, tenalla. 6. Àmfora itàlica, Dr. 1A. 7. Àmfora itàlica, Dr. 1C. 8. Campaniana A, F2252/Lamb. 5. 9. Comuna oxidada ibèrica, copa. 10. Campaniana A, F2825/ Lamb. 27Bb. 11. Comuna oxidada pintada ibèrica, decoració motius vegetals. 12. Comuna oxidada pintada ibèrica, càlat. 13. Comuna oxidada pintada ibèrica, decoració d'un cavall. 14. Comuna oxidada ibèrica, copa. 15. Àmfora itàlica, Dr. 1A. 16. Àmfora tripolitana antiga. 17. Àmfora ibèrica. 18. Comuna oxidada pintada ibèrica, càlat. 19. Got de fireta. 20. Àmfora itàlica, Dr. 1A. 21. Àmfora ibèrica. 22. Comuna oxidada ibèrica, tenalla. 23. Comuna oxidada pintada ibèrica, tenalla. 24.

Comuna itàlica, F2 Torre Tavernera. 25. Comuna itàlica, F2 Celsa 80.7056. 26. Grollera oxidada ibèrica, olla de cocció.

27. Grollera reduïda ibèrica, olla de cocció. 28. Comuna oxidada, tapadora. 29. Comuna oxidada ibèrica, gerra. 30 i 31. Fusaioles. 32. Ham de bronze. 


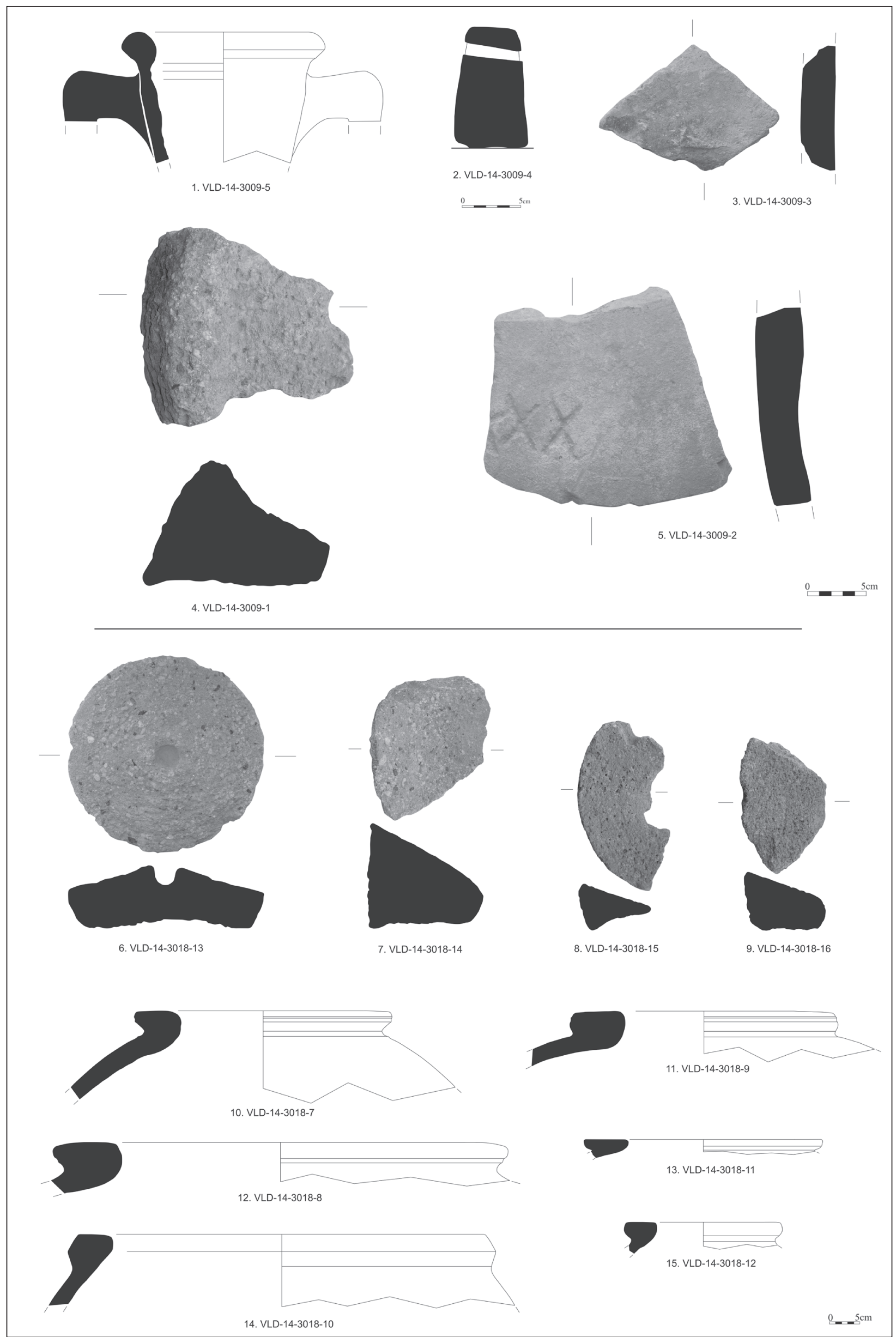

Figura 10. Material significatiu de les UE 3009 i 3018. 1. Àmfora tarraconense, Dr. 2B. 2. Pondus. 3. Fragment de dolium amb restes de titulus pictus en ocre. 4. Fragment de catillus de granit. 5. Fragment de dolium amb marca de capacitat: “... XXX". 6. Meta de conglomerat. 7 i 8. Catilla de conglomerat. 9. Catillus de granit. 10-15. Dolia. 


\section{Sitja 3017}

Aquesta sitja conservava una profunditat de $2,8 \mathrm{~m}$, i estava farcida per un estrat de terra solta de color marró amb barreja de pedres irregulars. ${ }^{32}$ El conjunt de materials que va proporcionar estava format per 1.346 peces, de les quals 126 són restes d'animals, 11 de metall, 5 d'elements petris, 1 stilus d'os i 1.204 fragments ceràmics (figures 10 i 11). Entre els estris de metall trobem eines i claus de ferro, i també algun clau de bronze; mentre que en els elements de pedra recuperats destaquem 4 molins rotatoris i 1 pedra d'esmolar.

Quant al conjunt de vaixella recuperat, hem de fer esment d'importacions d'àmfores de l'àmbit púnic, amb presència de contenidors ebusitans i del Cercle de l'Estret, juntament amb envasos itàlics representats per les produccions pròpies del període tardorepublicà, com són la grecoitàlica i les tres variants de la Dr. 1. Es completa el grup amb envasos per al transport de l'oli bètic del tipus Dr. 20 i també contenidors Haltern 70, als quals hem d'afegir les produccions d'àmfores de vi catalanes, dels tipus Pascual 1, Dr. 2A i Dr. 3A. Entre la vaixella fina hem de fer esment de la presència de vernís negre del tipus Campaniana $\mathrm{A}$ i B de Cales, aquesta última amb vasos de les formes Lamb. 1/F 2322, Lamb. 7/F 2280-84, Lamb. 5/F 2257 i F 4753. Es completa el grup de la ceràmica fina de taula amb la vaixella de vernís vermell itàlic, on hem identificat les formes Consp. 11.1, 18.1 i 26, a més d'un fons amb segell central, en cartel.la quadrada i inscripció en dues línies ${ }^{33}$ (figures 11,20 i 14,4), on es pot llegir "P (I?)M/(?)IU(S?)".

De la vaixella fina també hem recuperat vasos de parets fines dels tipus Mayet 2, 2.1, 14, 14A i 21, a més de fragments indeterminats de vaixella de vidre. Pel que fa al grup de la ceràmica comuna, trobem produccions locals de tradició ibèrica llisa, com ara una olla d'emmagatzematge i una tenalla de la ibèrica pintada, a la qual hem de sumar tres olles de cocció de la ceràmica grollera ibèrica. Respecte a les importacions destaquen les itàliques, amb cassoles Vegas 14 i tapadores F3 Celsa 80.8145, acompanyades del plat de roig intern pompeià F6 Luni 5 . La resta de peces del grup de la ceràmica comuna corresponen a la denominada ceràmica comuna romana, on hem de fer esment de la presència de morters, gibrells, escudelles, gerretes, olles d'emmagatzematge i també fragments de dolia amb les seves corresponents tapadores. Finalment, al conjunt ceràmic descrit hem d'afegir peces de material constructiu com tegulae i imbrices, i també diversos pondera.

Hem de destacar, dintre d'aquest darrer grup, la presència d'algunes peces segellades. D'una banda, tenim una tegula que conserva part d'un segell dintre de cartel.la rectangular ${ }^{34}$ on es pot llegir "POM..." (figures 11,27 i 14,6), i del qual hem localitzat un

32. Codificat com UE 3018.

33. La cartel.la té unes mides de $15 \mathrm{~mm}$ de costat, i li falta l'angle superior dret, ja que la base de la copa està trencada en aquest punt.

34. La seva alçada és de $17 \mathrm{~mm}$ i l'amplada conservada de $36 \mathrm{~mm}$. altre exemplar en la sitja UE 3017. Es tracta d'un tipus de marca sobre tegula del qual tenim paral.lels a la ciutat de Tàrraco i al seu entorn, concretament a la vil.la de Barenys, amb la llegenda POMPEI i que correspondria al gentilici Pompeius (Berni 2010: 199).

Finalment, també tres dels pondera recuperats presentaven epigrafia. Tots tres havien estat treballats en la part superior formant una mena de cartel.la rectangular en positiu, sobre la qual es va escriure "NBEN" en majúscula, amb les dues $\mathrm{N}$ retrògrades obrint i tancant la inscripciós (figures 11,31-33 i 14,9-11). Tenim documentat un paral.lel d'un altre pondus amb inscripció procedent del Tossal de Manises (Alacant), en aquest cas també en la cara superior, on es llegeix "LUCANI", i que ha estat interpretat com el nom del propietari (Rabanal, Abascal 1985: 198). Però la dada més interessant és que la lectura que podem fer d'aquesta inscripció és N.BEN, referent al gentilici d'origen itàlic Bennius. ${ }^{36}$ Es tracta d'un personatge documentat en la propera vil.la del Vilarenc, situada a la població de Calafell, a tan sols $4,1 \mathrm{~km}$ al sud-est del nostre jaciment, en inscripcions sobre tegulae datades a època augustal amb la marca CN.BEN - Cnaei Bennii- (Revilla 2007: 106). D'aquesta manera, no podem descartar que aquestes peces procedeixin del Vilarenc, si bé allà els materials documentats amb el nomen Bennius estan sempre associats al praenomen Cnaei $-\mathrm{CN}-$, i en el nostre cas no podem determinar amb seguretat si la lletra N del praenomen correspon a un Cnaei i no es va poder inscriure sencera per falta d'espai, o bé és d'un altre personatge associat a aquesta família amb un praenomen iniciat amb $\mathrm{N}$, tal vegada Numerius. El que sembla corroborar aquesta troballa és la presència d'aquesta família com a propietaris a l'ager Tarraconensis, tant al sector del Baix Penedès (el Vilarenc, la Devesa) com al Tarragonès, on tenim una inscripció funerària d'un L. Bennius Primigenius a la vil.la de Mas de Sardà (la Pobla de Mafumet) datada a l'època flàvia (Gorostidi et al. 2013: 410-411), o a la mateixa Tàrraco als segles II-III (Revilla 2007: 106). A més, hem de destacar que la marca CN.BEN apareix sobre tegulae, a més del Vilarenc, a Tàrraco i a Empúries (Gorostidi et al. 2013: nota 15).

\section{Sitja 3035}

Aquesta sitja, de la qual es conservava una profunditat màxima de 2,6 m, estava reblerta per un únic

35. El primer dels pondera (VLD-14-3018-1) inscrit es caracteritza perquè les grafies tenen una alçada mitjana de 14 mm i ocupen una amplada de $42 \mathrm{~mm}$, amb els traços imitant el cisellat de la lletra capital sobre suport lapidi, com es pot comprovar en els traços de les $\mathrm{N}$, principalment. El segon (VLD-14-3018-2) presenta una alçada mitjana de les lletres de $12 \mathrm{~mm}$, amb una amplada de la inscripció de $39 \mathrm{~mm}$, i les mateixes característiques epigràfiques que la precedent. El tercer pondus (VLD-14-3018-3), de característiques anàlogues als altres dos, es caracteritza per una alçada de les grafies de $14 \mathrm{~mm}$ i una amplada total de l'àrea inscrita de $33 \mathrm{~mm}$.

36. Volem agrair les valuoses observacions al respecte que ens han fet els col-legues P. Berni, D. Gorostidi i V. Revilla. 


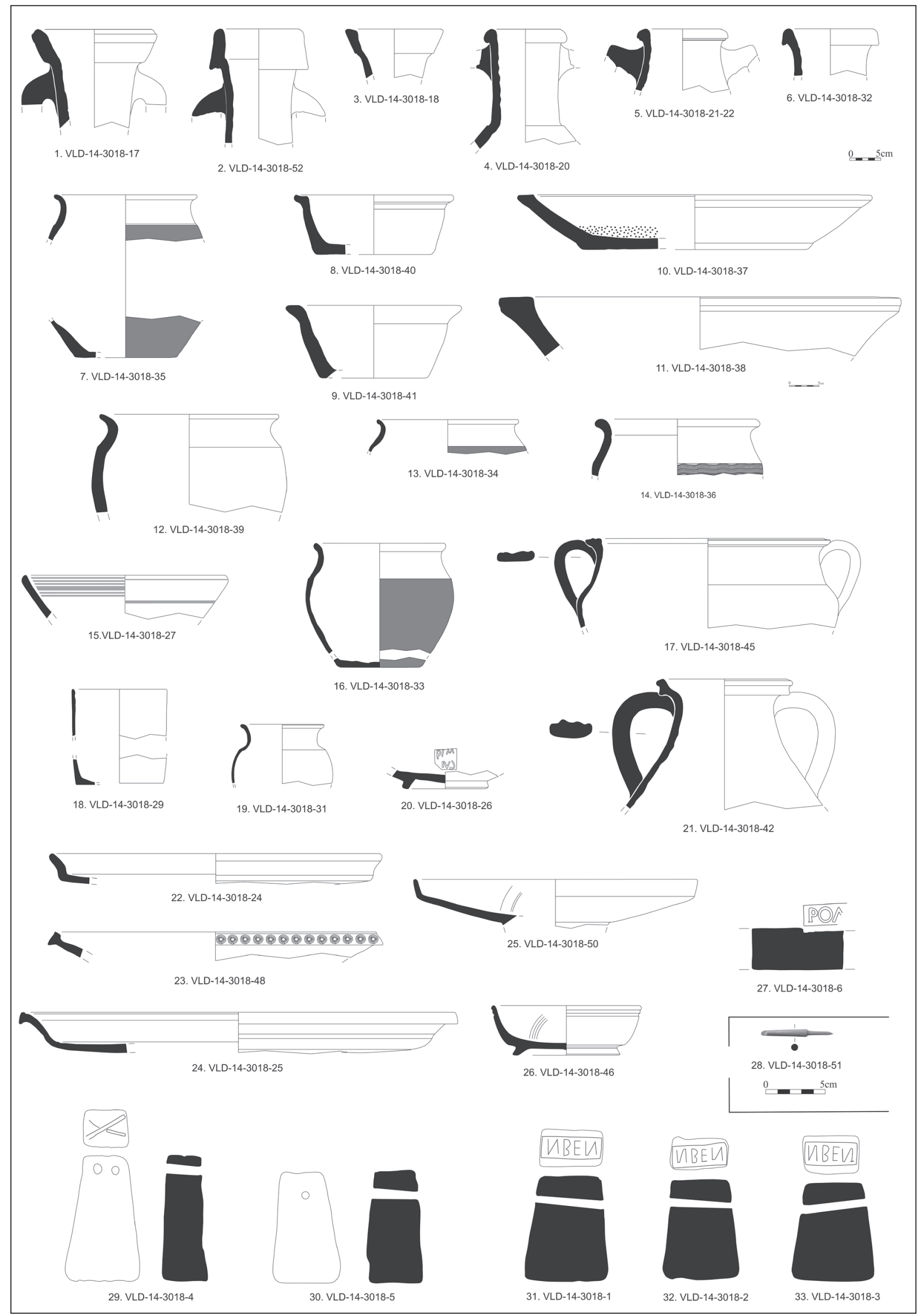

Figura 11. Material significatiu de la UE 3018. 1 i 3. Àmfora bètica, Haltern 70. 2. Àmfora itàlica, Dr. 1C. 4. Àmfora tarraconense, Dr. 2A. 5. Àmfora tarraconense, Dr. 3A. 6. Àmfora tripolitana antiga. 7. Grollera oxidada, olla de cocció. 8 i 9. Comuna oxidada, gibrell. 10 i 11. Comuna oxidada, morter. 12 i 17. Comuna oxidada, olla d'emmagatzematge. 13 i 16. Grollera reduïda, olla de cocció. 14. Grollera oxidada, olla d'emmagatzematge. 15. Comuna oxidada pintada romana, escudella. 18. Parets Fines, Mayet 14. 19. Parets Fines, Mayet 21. 20. TS itàlica amb segell en dues línies "P (I?)M/(?)IU(S?)". 21. Comuna oxidada, gerreta. 22. TS itàlica, Consp. 18.1. 23. Vernís negre de Cales, F4753. 24. TS itàlica, Consp. 11.1. 25. Vernís negre de Cales, F2284/Lamb. 7. 26. Vernís negre de Cales, F2322/Lamb. 1. 27. Fragment tegulae segell "POM...”. 28. Stilus d'os. 29 i 30. Pondera. 31-33. Pondera amb inscripció "NBEN". 
estrat de terra, ${ }^{37}$ de textura solta i color marró fosc, amb presència d'algunes pedres calcàries irregulars (figura 4,3). El conjunt de materials recuperats del seu interior ascendeix a 396 fragments, dels quals 21 són restes animals, 5 són fragments de metall, amb claus i eines de ferro i una làmina de bronze, i 1 una pedra d'esmolar (figura 12). Els 369 restants conformen el grup de la ceràmica, on trobem àmfores d'importació eivissenques i del Cercle de l'Estret, envasos itàlics del tipus Dr. 1A i àmfores de vi catalanes dels tipus Pascual 1 i Dr. 2A. Respecte al conjunt de la vaixella de fina, hem de destacar la presència de vaixella de vidre, vernís negre de Cales i de procedència indeterminada, així com vasos de vernís vermell tant de producció itàlica, formes Consp. 11 i 36.4, com de producció sud-gàl-lica, copes Drag. 18 a i 24/25a. Passant a la ceràmica comuna, hem de fer esment de les produccions locals ibèriques, tipus tenalles, a les quals cal sumar-hi olles i cassoles de cuina en grollera ibèrica oxidada. També trobem alguna importació de cuina itàlica, la forma de la qual no es pot determinar a partir dels fragments recuperats, i ceràmica del grup de la comuna romana, amb olles d'emmagatzematge, morters, gerretes, ampolles, plats, pàteres, tapadores i gibrells. Finalment, hem de mencionar la troballa d'un petit gobelet — de fireta- que imita els vasets bicònics de producció de grisa de la costa catalana.

En l'àmbit cronològic, les dades que proporciona l'estudi del material recuperat d'aquestes sitges, ens ofereix la producció típica que trobem al llarg del període tardorepublicà, com ara les àmfores grecoitàliques i del tipus Dr. 1 en les seves tres variants, junt amb exemplars indeterminats de Bríndisi, nordafricans T-7.5.2.2. i tripolitans, a més de vaixella de vernís negre napolitana del tipus A i B de Cales. Amb aquests materials trobem també peces de datació més baixa, com les àmfores bètiques del tipus Haltern 70 i Ovoide 2, que, juntament amb les tarraconenses Pascual 1, són pròpies de la segona meitat del segle I aC. Hem de mencionar, a més, un conjunt vascular que es comença a produir a inici o mitjan del darrer quart del segle I aC, com són els vasos de parets fines Mayet 14A i 21, les importacions de sigil.lada itàlica formes Consp. 18.1, 11.1 i les àmfores Dr. 2 i Dr. 3. Però encara hem de fer esment de peces que no es comencen a produir i comercialitzar fins al canvi d'Era, com és la Consp. 26, o ja en un moment avançat del primer quart del segle I dC, com són les formes Consp. 36.4 de TS itàlica o les Drag. 18 i 25/25a de TS sud-gàl-lica, que es comencen a fabricar vers el $15 \mathrm{dC}$, arribant en els casos de la producció sud-gàl-lica als anys 60 i 40 dC, respectivament. D'aquesta manera, hem de datar el colgament d'aquestes sitges en un període que va de final del primer quart del segle $\mathrm{I} \mathrm{dC}$ a l'inici de la segona meitat d'aquesta centúria. De fet, una cronologia que coincideix amb la del conjunt ceràmic recuperat del farciment constructiu de les estructures de la tercera fase, com ja havíem exposat.

37. Codificat com UE 3036.

\section{El colgament de la darrera sitja $i$ l'abandonament del jaciment}

L'última de les sitges excavades per nosaltres és la codificada amb el número 3015. Les dades cronològiques de l'estudi del seu material, coincideixen grosso modo amb les que es deriven del conjunt recuperat de l'estrat de colgament de les restes d'època antiga, codificat amb la UE 3002, com ara veurem.

\section{Sitja 3015}

Aquesta sitja estava reblerta per un únic estrat de terra, ${ }^{38}$ de textura solta i color marró fosc, amb presència de pedres calcàries heteromètriques. La seva fondària màxima conservada era de 2,5 metres (figura 4,4). El conjunt de materials que es va recuperar de l'excavació del seu farciment era de 877 fragments (figura 12), dels quals, 197 eren restes d'animals i 13, peces de metall, entre les quals tenim una moneda, concretament un as de l'emperador Tiberi datat al $15 \mathrm{dC}^{39}$ i dos aplics de cavalleria militar tipus Bishop 7, 7b o 7e (figures 12,24-25 i 14,13-14), propi del període que va dels emperadors Claudi i Neró fins a final d'època flàvia (Bishop 1988: 96-98, 149, fig. 46). La resta de fragments, en total 610, són peces ceràmiques, entre les quals trobem diverses importacions amfòriques de l'àmbit púnic, com ara ebusitanes i del Cercle de l'Estret, juntament amb envasos de la franja tirrènica d'Itàlia, una àmfora oleària bètica del tipus Dr. 20B datada en el segon quart del segle I $\mathrm{dC}$, i àmfores de fabricació local o regional com són les catalanes Pascual 1 i Dr. 2A. Acompanyant aquest conjunt tenim també vaixella fina, on trobem peces de la producció de vernís negre napolità del tipus A i també calenes, junt amb ceràmica de vernís vermell, entre les quals destaca una copa Consp. 23 de TS Itàlica amb segell central in planta pedis on es llegeix “ATEI.A” (figures 12,7 i 14,5), una producció que s'inicia a Arezzo vers el $15 \mathrm{aC}$, però que estendrà les seves filials per Lió, Pisa i la Graufesenque fins a final d'aquesta centúria i durant els primers anys del segle I dC (Roca 2005: 87), i que tenim present a Tàrraco amb un segell anàleg recuperat a les excavacions del Passatge Cobos (Tarrats 1992: 158, fig. 1, 7). Es completa el repertori de vernís vermell amb la producció de TS Sud-gàl-lica, present amb un plat Drag. 18a i una copa Drag. 30a, i una copa de TS Hispànica també del tipus Drag. 18. Completa el grup de la vaixella fina un gobelet de parets fines tipus Mayet 35 i un altre probablement de la forma Mayet 36, i a l'últim, dues copes de vaixella de vidre. Dins del grup de la ceràmica comuna, cal destacar les importacions de cuina itàlica, com ara la tapadora F5 Celsa 79.15, i una cassola de roig intern pompeià del tipus F1 Celsa VEL.53. També tenim importacions nord-africanes, concretament un lopas púnic i, ja de la producció de cuina africana altimperial, una

38. Codificat com UE 3016.

39. Les dades sobre les monedes recuperades en la intervenció provenen de l'estudi numismàtic que ha realitzat la nostra collega Imma Teixell Navarro, a qui volem agrair la seva valuosa col-laboració. 


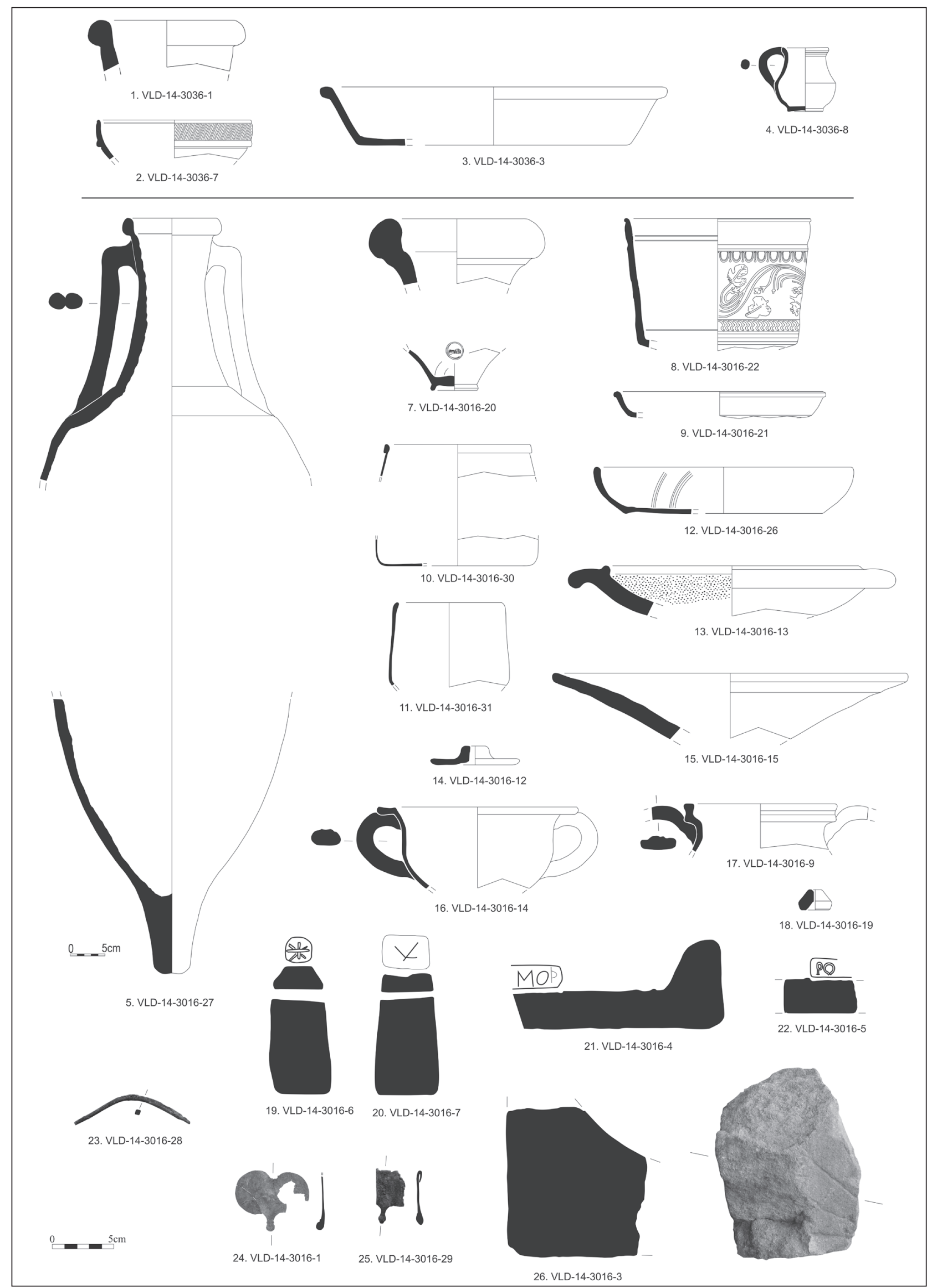

Figura 12. Material significatiu de les UE 3036 i 3016. 1. Àmfora tarraconense, Dr. 2A. 2. TS Sud-gàl-lica, Drag. $24 / 25 a .3$. Grollera reduïda, cassola baixa. 4. Gobelet de fireta. 5. Àmfora tarraconense, Dr. 2A. 6. Àmfora bètica, Dr. 20B. 7. TS itàlica, Consp. $23 \mathrm{amb}$ segell in planta pedis "ATEI.A". 8. TS Sud-gàl-lica, Drag. 30a. 9. TS Sud-gàl-lica, Drag. 18a. 10 i 11. Gots de vidre. 12. Cuina africana, Lamb. 10B. 13. Comuna oxidada, morter. 14. Comuna oxidada, tap d'àmfora. 15. Comuna oxidada, plat-tapadora. 16. Comuna oxidada, olleta. 17. Comuna oxidada, gerreta. 18. Fusaiola. 19 i 20. Pondera. 21. Fragment tegulae amb segell “...MO". 22. Fragment tegulae amb segell "PO...". 23. Agulla de cosir de bronze. 24. Aplic de bronze, Bishop 7b o 7e. 25. Aplic de bronze, Bishop 7. 26. Fragment de rellotge de sol, en pedra lumaquel.la. 
tapadora Ostia II fig. 302 i una cassola Lamb. 10B. La resta del conjunt de ceràmica comuna el formen les produccions ibèriques, on destaquem un gobelet i una tenalla d'emmagatzematge. Dins de la ceràmica comuna romana hem recuperat olles de cocció, tapadores i morters de vaixella de cuina, una copa del repertori de taula i diverses olles d'emmagatzematge. Es completa el conjunt ceràmic amb una llàntia de volutes del tipus Deneuve VE, un ungüentari, una fusaiola i dos pondera, que presentaven unes marques característiques en la part superior, incises quan les peces eren fresques, amb forma de grafit d'estrella de vuit i de cinc puntes, respectivament. També hem recuperat fragments de material constructiu, com imbrices i tegulae. Entre les segones destaca la presència de dues peces que estaven segellades, la primera amb la inscripció "PO..." dintre d'una cartel.la rectangular, ${ }^{40}$ similar al segell de la sitja UE 3017, però en aquest cas amb la grafia de la O oberta per la part inferior. Seguint els paral-lels abans citats, creiem que podria correspondre a la lectura POMPEI (Berni 2010: 199). La segona conserva la part final de la inscripció, i es pot llegir “...MO” amb la marca del segell al costat de la $\mathrm{O}$, i dintre d'una cartel.la rectangular ${ }^{41}$ (figures 12,21-22 i 14,7-8).

Dins del material lapidi en destaca la recuperació d'un fragment de rellotge de sol en pedra sorrenca lumaquel.la de color gris (figura 12,26). En relació amb aquest fragment, hem de dir que no es tracta d'una troballa gaire comuna, però tampoc excepcional, ja que s'han trobat altres rellotges de sol a Catalunya, com, per exemple, el recuperat a l'interior d'una sitja de la vil.la romana de mas d'en Gras (Sánchez i Járrega 2008: 112-113), un altre identificat en un estrat d'abandonament datat al 50 aC de la casa 2 a la zona 0 del jaciment de Darró (Gumà 1992: 145157), el localitzat la vil.la romana de Can Paxau de Badalona (Balil 1982: 147-148, làm. 9, fig. 3), el del jaciment de Ses Alzines de Tossa de Mar (Burch et al. 2005, 52-53 i 57), el recuperat en un estrat d'abandonament de final del segle I dC o d'inici del segon dC de l'anomenada fossa 9 a la vil.la romana del Bosquet o era del Moro de Sant Pere de Ribes (Bosch i Miret 1989: 151 i 159), el de la vil.la romana de Florejachs de Guissona, i d'altres fragments recollits en nivells superficials o sense estratigrafia arqueològica, com ara el rellotge dels Obachs a Ciutadilla, el de Can Feliu a Rubí i el del camí prop de n'Oriol i can Sant Joan, també a Rubí (Gumà 1992: 155-156).

A nivell cronològic, les dades més interessants ens les proporciona una producció que fins ara no havíem documentat, com és la cuina africana. Dels dos exemplars recuperats en destaca la cassola forma Lamb. 10B, que es data a partir d'època flàvia, arribant a mitjan segle III dC. Igualment hem de mencionar la presència de formes que es comencen a produir a mitjan segle I dC, absents en els contextos anteriors, com són els vasos de sigilllada hispànica, i més concretament amb la forma Drag. 18, i també la llàntia

40. Té una alçada de $16 \mathrm{~mm}$ i una amplada conservada de $34 \mathrm{~mm}$.

41. La seva alçada és de $19 \mathrm{~mm}$ i la seva amplada conservada, de $42 \mathrm{~mm}$. de volutes del tipus Deneuve VE, que es comença a fabricar en el primer quart del segle i dC i perdura fins a final d'aquesta centúria. A més, disposem de la presència de l'aplic de cavalleria Bishop 7, que té una cronologia precisa situada entre el 41 i el 96 dC. Alhora, hem de destacar l'absència de materials produïts clarament a partir de final del segle I dC o bé ja durant l'inici del següent, de manera que hem de plantejar el colgament d'aquesta sitja durant el darrer terç del segle I dC, tal vegada en un moment inicial d'aquest període, si bé el material recuperat no ens permet precisar més aquesta datació.

\section{L'estrat d'abandonament general 3002}

Cobrint les últimes construccions de la darrera fase d'ús del jaciment tenim aquest estrat, que va proporcionar un conjunt de materials format per 3.437 fragments, dels quals 391 són restes d'animals, 92 són de material constructiu, 29 són peces metàl-liques, 2 són materials lítics, i els 2.923 restants són fragments ceràmics (figura 13). Pel que fa al conjunt ceràmic, aquest no difereix gaire del que hem presentat per al rebliment de la sitja 3015, i presenta material característic de tot el període d'ocupació del jaciment, és a dir, del segle II aC fins a final del segle I dC. Així, d'època tardorepublicana trobem àmfores de Bríndisi i de la zona tirrènica amb les tres variants de Dr. 1, a les quals hem de sumar les tripolitanes antigues, juntament amb alguns contenidors ja característics del segle $\mathrm{I} \mathrm{aC}$, com ara les sud-hispàniques Dr. 7-11, Haltern 70, Ovoide 2, i d'altres més pròpies dels inicis del període augustal com són les àmfores tarraconenses Oberaden 74 i Pascual 1. Es completa amb envasos que tenen el seu moment de producció inicial a final d'aquesta centúria, com són les itàliques Richborough 527 o les tarraconenses Dr. 2.

Entre la ceràmica comuna trobem les produccions indígenes pròpies del període ibèric tardà, com són els càlats, les tenalles i les gerres, a més de vaixella de cuina de producció grollera acompanyada de ceràmica comuna romana $\mathrm{i}$ importacions de ceràmica de cuina itàlica i també africana, aquesta última amb la cassola Ostia II fig. 303, datada des d'època de Tiberi i documentada al llarg de la primera meitat del segle II dC.

Quant a la vaixella fina, tenim representades les produccions de vernís negre de la Campània, amb plats i pàteres de la producció $A$ antiga, mitjana i tardana, com són les formes Lamb. 23, 55, 5 i 5-7, juntament amb vasos de la B de Cales, present amb les formes Lamb. 1, 5, 10 i 8b. Es completa el repertori de la vaixella fina amb les produccions de vernís vermell, amb vaixella TS itàlica representada per formes que es produeixen ja a final del segle I aC com les Consp. 11.1.4, 18.2, 20 i 33, o ja des d'època de Tiberi, com és la forma Consp. 4.6.1. Però la més destacada, cronològicament, és la presència d'una pàtera Consp. 20.4, datada entre els anys 40-80 dC. $\mathrm{Al}$ conjunt cal sumar-hi també la presència de produccions sud-gàl-liques, amb formes primerenques com la Drag. 15a, 29a, 18a i Ritt. 9b, que, això no obstant, perduren fins a l'inici de la segona meitat del segle i dC o fins a l'inici de l'època flàvia, com és el 


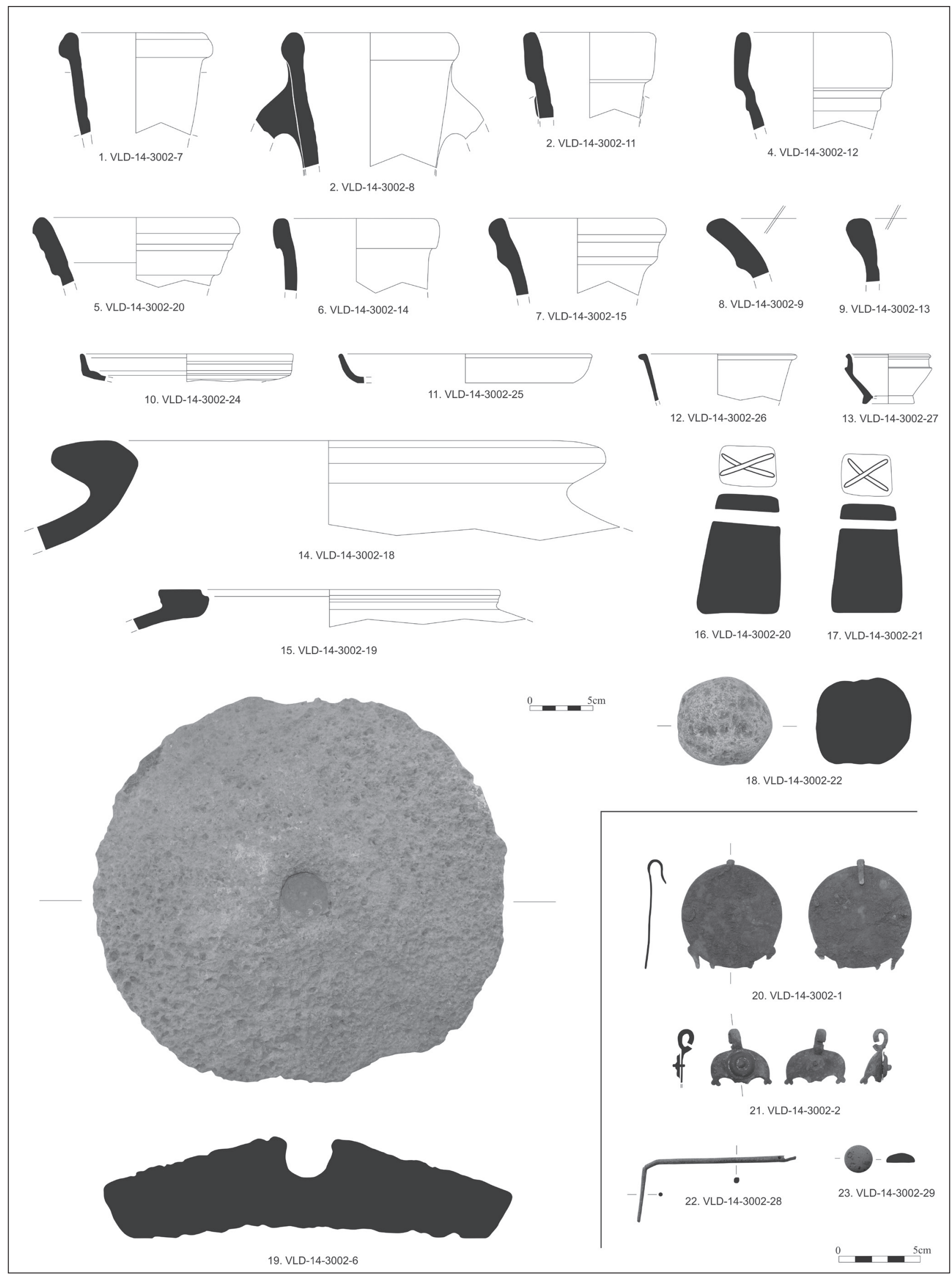

Figura 13. Material significatiu de la UE 3002. 1 i 2. Àmfora tarraconense, Dr. 2. 3 i 4. Àmfora bètica, Haltern 70.5 i 8. Àmfora sud-hispànica, Dr. 7-11. 6. Àmfora bètica, Ovoide 2. 7. Àmfora tarraconense, Oberaden 74. 9. Àmfora bètica, símil Ovoide 6. 10. TS Sud-gàl-lica, Drag. 15a. 11. TS Sud-gàl-lica, Drag. 18a. 12. TS Sud-gàl-lica, Ritt. 9b. 13. TS Sud-gàl-lica, Ritt. 5c. 14 i 15. Dolia. 16 i 17. Pondera. 18. Possible projectil de quars. 19. Meta de pedra volcànica. 20. Aplic de bronze, Bishop 3a o 3b. 3. 21. Aplic de bronze, Bishop 8n. 22. Agulla de cosir de bronze. 23. Fitxa de joc de pasta de vidre de color groc. 
cas particular de la Ritt. 9b. Es completa el repertori d'aquesta producció amb vasos que es comencen a fabricar a inici-mitjan del segon quart del segle i dC, i que també poden arribar a inici del darrer quart, com una dubtosa Drag. 27b i una Ritt. 5c.

Finalment, hem de fer esment de la presència d'altres objectes, a més de molins rotatoris de pedra volcànica, diversos pesos de teler o pondera amb marques incises en la part superior en forma d'aspa, i d'una sèrie de peces metàl.liques, entre les quals cal destacar una clau de porta de ferro, agulles de cosir, un anell, una fíbula de bronze i tres monedes, de les quals s'ha pogut identificar un as d'Iltirta datat entre el 80 i el $72 \mathrm{aC}$, i un as de Tiberi emès l'any $15 \mathrm{dC}$. Cal destacar també, entre aquestes peces metàl-liques, dos aplics de cavalleria militar, dels tipus Bishop 3a o 3b i Bishop 8n (figures 13,20-21 i 14,15-16), datats entre el govern de Neró i els darrers anys de la dinastia flàvia i des d'època augustal fins a final del segle I dC, respectivament (Bishop 1988: 96-98, 145, 152, fig. 44, 47).

Hem d'enumerar també una fitxa de joc de pasta de vidre i varis fragments d'escòria de vidre, testimoni d'altres tipus d'activitats no relacionades directament amb els treballs de conreu, recol-lecció, emmagatzematge i preparació del gra, sinó més aviat amb la vida productiva i quotidiana del jaciment. Val a dir que la migradesa de les restes estructurals documentades així com el poc espai intervingut no ens ha permès localitzar aquells espais o àmbits associats a aquests processos.

Tenim doncs un context de materials que semblen procedir del remenat i desmuntatge de les estructures i els nivells d'ús i/o constructius que encara es conservaven en el moment d'abandonar el jaciment. Veiem que aquest material sembla pertànyer als darrers ocupants d'aquest jaciment i que caldria associar amb els atuells abandonats que restaven entre les estructures arquitectòniques quan aquestes foren abandonades o restaren obsoletes. Plantegem per a aquest moment, i en virtut del material recuperat, una datació que es trobaria entorn de final de la dinastia julioclàudia o inici de la flàvia.

\section{Conclusions}

Com ja hem apuntat a la introducció, la profunda alteració provocada pels treballs agrícoles (llaurada i espoli), l'erosió i arrasament de les estructures i nivells arqueològics, a més del fet que l'excavació arqueològica es va aturar en diferents punts per qüestions alienes a la direcció arqueològica, han estat un handicap en l'estudi del jaciment. Aquests condicionants ens impedeixen plantejar en alguns dels sectors excavats precisions cronològiques, atribucions funcionals o interpretacions plenament fonamentades que vagin més enllà de les meres suposicions, a més de no poder confirmar ni desmentir l'existència d'altres possibles troballes en aquells punts on no s'ha pogut intervenir.

Així doncs, i amb les dades actuals, es poden establir unes línies generals amb relació al comportament històric-arqueològic d'aquest jaciment, que sembla mostrar-se com un lloc relacionat amb l'ocupació i explotació de tipus agrari d'aquest sector de l'ager Tarraconensis.

La primera fase d'ocupació antròpica detectada al jaciment es remunta, com ja hem explicat, a la segona meitat del segle $\mathrm{II} \mathrm{aC}$, i està relacionada $\mathrm{amb}$ l'adequació d'aquesta àrea i amb l'excavació d'un camp de sitges. No podem determinar que totes les sitges fossin construïdes al mateix moment, tot i que, com ja hem explicat, foren amortitzades de manera diacrònica. L'assentament primigeni i el material contingut en les sitges en els diversos moments posteriors d'ús i reforma, sembla estar clarament relacionat amb l'explotació agrícola d'aquest sector de l'ager Tarraconensis, concretament per a la producció i emmagatzematge de cereal. ${ }^{42}$

Així doncs, aquest excedent de gra per al seu posterior consum en moments de mala collita, o bé per a la seva comercialització-distribució, s'emmagatzemaria en les sitges excavades al subsòl, tot i que la presència de grans contenidors tipus dolia recuperats entre el material de colgament d'algunes de les sitges, també ens estaria indicant un probable ús compartit o d'introducció progressiu d'aquest nou sistema "romà" d'emmagatzematge del gra, tot i que no podem descartar que s'hagués emprat també per a altres productes tan característics d'aquesta zona, com podria ser el vi. ${ }^{43}$ De fet, es tracta d'un jaciment que té unes bones possibilitats d'explotació i intercanvi comercial, gràcies a la proximitat d'un destacat eix viari que connectava l'interior amb la costa, com és l'actual riera de la Bisbal (figura 1), i a un altre eix viari no menys important, com és el pas de la Via Augusta, distants entorn els 640 i els 340 metres de la Devesa, respectivament. A més, entre els materials documentats apareixen constantment peces relacionades amb la transformació del gra, com són els nombrosos molins documentats, que juntament amb elements de la vida quotidiana com ara pondera, materials constructius com tegulae, imbrices o tovots, posen de manifest la presència d'un assentament humà estable en relació amb l'explotació agrícola d'aquest lloc, des de la segona meitat del segle II aC i fins almenys l'època flàvia.

Les restes estructurals exhumades, que se superposen al sitjar tardorepublicà a partir de la primera meitat del segle I aC (fase dos), no ens permeten dir si formarien part d'algun assentament de petites dimensions, tipus granja, fundada durant els primers anys de la conquesta romana, i ocupat bé per població autòctona redistribuïda o bé per colons romans i itàlics (Prevosti 2010: 61-63 i 66). Per contra, les restes associades a la fase posterior, la tres, sí que podrien ser interpretades com a part d'una vil.la, ${ }^{44}$

42. La manca d'analítiques del sediment de les sitges ens impedeix determinar quin tipus de cereal seria el que s'emmagatzemava, si blat comú o altres tipus.

43. De fet, a poca distància tenim dos exemples, com serien els centres del Vilarenc (Calafell), situat a $4,1 \mathrm{~km}$ al sud-est, el centre de Tomoví (Albinyana/Banyeres del Penedès), situat a 4,5 km al nord, i un tercer una mica més llunyà, que és el jaciment de la Clota (Creixell), situat $9 \mathrm{~km}$ al sud-oest.

44. Val a dir que les primeres vil.les d'explotació documentades a l'ager Tarraconensis s'edifiquen i proliferen sobretot a 


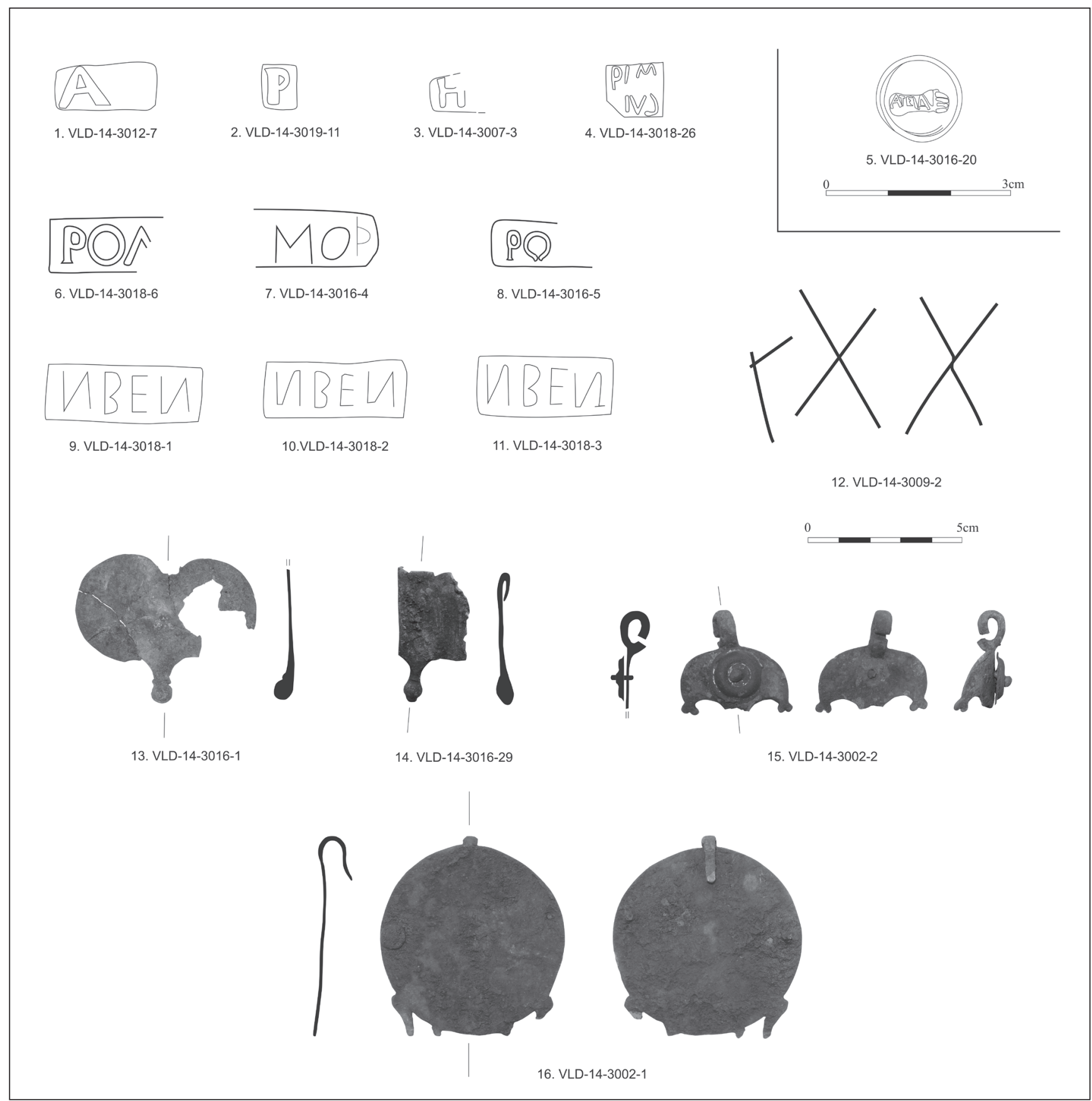

Figura 14. 1. Detall dels segells documentats: àmfora grecoitàlica bd2 amb segell "A...”. 2. Àmfora tarraconense amb segell "P". 3. Àmfora sud-hispànica Ovoide $2 \mathrm{amb}$ segell "H...". 4. TS itàlica amb segell en doble línia "P (I?)M/(?)IU(S?)". 5. TS Itàlica amb segell in planta pedis "ATEI.A". 6. Segell sobre tegula "POM...". 7. Segell sobre tegula "...MO". 8. Segell sobre tegula "PO...". 9, 10 i 11. Pondera amb inscripció "NBEN". 12. Dolium amb grafit post cocturam “...XXX". 13. Aplic de cavalleria militar tipus Bishop 7b o 7e. 14. Aplic de cavalleria militar tipus Bishop 7. 15. Aplic de cavalleria tipus Bishop 8n. 16. Aplic de cavalleria militar tipus Bishop 3a o 3 b.

sense excloure, però, una coexistència amb altres assentaments de caire rural, sota el control de colons o petits propietaris encarregats de l'explotació d'una part del fundus de la vil.la de la qual podrien dependre (Prevosti 2007: 71-73).

La troballa de quatre aplics de cavalleria militar entre el material exhumat del darrer moment d'ocupació també ens podria fer pensar en l'existència

partir d'època augustal (López 2006: 100-104; Macias 2005: 79-82). d'un establiment per acollir alguna unitat de cavalleria amb funcions de policia rural (Aurrecoechea 1995-1996: 78, 88; 2007: 332, 337-338 i 343). Però el fet de no trobar més objectes militars, així com el gran volum de restes de caràcter agrícola (molins de pedra, tenalles per a l'emmagatzematge, dolia...), ens fa pensar en un context marcadament agrícola i un teixit social prou permeable que permet la interrelació entre el món civil i el militar (Fernández 2006: 271, 288 i 300).

El que sí queda clar és que cap a final del segle I dC, després d'uns dos segles i mig d'explotació i 
ocupació d'aquest espai, s'abandonà definitivament, coincidint amb el canvi d'estructura de poblament que es produeix en aquest moment i que es caracteritza per la disminució dels assentaments dispersos d'època republicana, la consolidació d'un tipus d'hàbitat més concentrat - la villa - la centuriació i organització del territori a partir d'un cadastre regular, així com possibles canvis en la propietat de la terra (Palet 2003: 129-161; Prevosti 2007: 71-72; 2010: 85).
Moisés Díaz García

Codex-ICAC

Pl. Sant Fructuós, 1 - 43002 Tarragona moisesu@msn.com

Josep Francesc Roig Pérez

Pl. Sant Fructuós, 1 - 43002 Tarragona jfroig@tinet.cat

\section{Bibliografia}

Aguarod, C. (1991). Cerámica romana importada de cocina en la Tarraconense. Institución Fernando el Católico. Saragossa.

Aquilué, X., García Roselló, J., Guitart, J. (coords.) (2000). La ceràmica de vernís negre dels segles II $i$ I aC: centres productors mediterranis $i$ comercialització a la Península Ibèrica. Taula rodona. Empúries 4 i 5 de juny de 1998. Mataró.

ARraYÁs, I. (2003). El territorium de Tàrraco en època tardo-republicana romana (ss III-I aC.). Poblament i estructures rurals al camp de Tarragona. Butlletí Arqueològic, èp. V, núm 25 (Reial Societat Arqueològica Tarraconense. Tarragona): 25-55.

ARraYÁs, I. (2004). Morfología histórica del territorium de Tarraco en época tardorepublicana romana (ss. III-I a.C.). Dialogues d'Histoire Ancienne 30, núm. 1. Université de Franche-Comté. Besançon: 33-60.

ArrayÁs, I. (2005). Morfología histórica del territorio de Tarraco (ss. III-I a.C.). Instrumenta 19. Universitat de Barcelona. Barcelona.

Asensio, D., Bruguera, R. (1996). Estudi estadístic sobre les produccions amfòriques d'època ibèrica al Baix Penedès. Miscel-lània Penedesenca, 1996 (Institut d'Estudis Penedesencs): 197-216.

Asensio, D., Ferrer, C., Morer, J., Pou, J., SAbATÉ, G. (1996). El poblament ibèric al Vendrell. Estat de la qüestió. Miscel-lània Penedesenca, 1996 (Institut d'Estudis Penedesencs): 55-69.

Aurrecoechea, J. (1995-1996). Las guarniciones de cinturón y atalaje de tipología militar en la Hispania
Romana, a tenor de los bronces hallados en la Meseta Sur. Cuadernos de Prehistoria y Arqueología Madrileñas, 10: 49-99.

Aurrecoechea, J. (2007). Arneses equinos de época romana en Hispania. A: Fernández, C. (ed.). Metalistería de la Hispania Romana. Sautuola XII. Santander: 321-344.

Balil, A. (1982). Esculturas romanas de la Península Ibérica V. Boletín del Seminario de Estudios de Arte y Arqueología, 48 (Valladolid): 120-150.

Benet, C., Burés, L., Carreté, J. M., Fàbrega, X., MaciAS, J. M., Remolà, J. A. (1992). Intervenció arqueològica en els assentaments iberoromans de l'Albornar (Baix Penedès). Revista d'Arqueologia de Ponent, 2 (Universitat de Lleida): 155-175.

Berni, P. (2010). Epigrafia sobre amphorae, tegulae, imbrex i dolia a l'àrea occidental del Camp de Tarragona. A: GorostidI, D. Les inscripcions romanes (IRAT), Ager Tarraconensis 3. Documenta 16. ICAC. Tarragona: 154-226.

Berni, P. (2015). Novedades de epigrafía anfórica en el Baix Llobregat. A: Martínez Ferreras, V. (ed.). La difusión comercial de las ánforas vinarias de la Hispania Citerior-Tarraconensis (s. I a.C.-I d.C.). Archaeopress Roman Archaeology 4. Oxford: 55-66.

Berni, P.; Miró, J. (2013). Dinámica socioeconómica en la Tarraconense Oriental a finales de la República y comienzos del Imperio. El comercio del vino a través de la epigafía anfórica. A: LópEz, J. (ed.). Tarraco Biennal. Actes del 1e. Congrés Internacional d'Arqueologia i Món Antic. Govern i societat a la 
Hispània romana. Novetats epigràfiques. Homenatge a Géza Alföldy. Volum 1. Tarragona: 63-83.

Berni, P., Revilla, V. (2008). Los sellos de las ánforas de producción tarraconense: representaciones y significado. A: Homenatge a Ricard Pascual i Guasch, Monografies 8. Barcelona: 98-111.

Bishop, M. C. (1988). Cavalry equipment of the roman army in the first century A. D. A: Coulston, J. C. (ed.). Military Equipment and the Identity of Roman Soldiers. British Archaeological Reports-International Series 394. Oxford: 67-197.

Bosch, J., Miret, J. (1989). L'excavació de la vil.la romana del Bosquet (Sant Pere de Ribes). Miscel-lània Penedesenca, 13 (Institut d'Estudis Penedesencs): 135-166.

Burch, J. (1996). L'ús de sitges en època republicana al NE de Catalunya. Revista d'Arqueologia de Ponent, 6 (Universitat de Lleida): 207-216.

Burch, J., Jiménez, M. F., Nolla, J. M., Palahí, L. (2005). El fundus de Turissa entre el segle I aC $i$ el I dC. Arqueologia de dos establiments rurals, Mas Carbotí $i$ Ses Alzines. Estudis Arqueològics 6. Girona.

CODEX (2008). Memòria d'intervenció arqueològica al jaciment "La Devesa". Pla Parcial "Can Cerdanyès" (El Vendrell, Baix Penedès). Memòria d'intervenció arqueològica inèdita dipositada a la Direcció General del Patrimoni Cultural. Generalitat de Catalunya. Tarragona.

Comas, M. (1997). Baetulo. Les marques d'àmfora. Corpus International des timbres amphoriques (fascicule 2). Union Académique International. Museu de Badalona.

DíAz, M. (2000). Tipocronología de los contextos cerámicos tardo-republicanos en Tarraco. Empúries, 52: 201-260.

Díaz, M. (en premsa). Las ánforas de Tarraco de los siglos II y I aC. Amphorae ex Hispania. Paisajes de producción y de consumo. III Congrés Internacional de la SECAH- Ex Officina Hispana. Tarragona. 10-13 desembre de 2014.

DíAz, M., ОтіÑA, P. (2003). Valoración comercial de Tarraco: importaciones cerámicas entre el siglo III a.C. y la dinastía julio-claudia. Bolskan, 20: 67-82.

Duch, J. (1976). Localización de un reloj de sol romano en Guimerà. Ilerda, XXXVII (Institut d'Estudis Ilerdencs. Lleida): 215-227.

Estrada, J. (1969). Vías y poblamiento romano en el territorio del Área Metropolitana de Barcelona. Comisión de Urbanismo 65. Barcelona.

Fernández, C. (2006). Post Vestigium Exercitus. Militaria romana en la región septentrional de la península Ibérica durante la época altoimperial. A: MoriLlo, A. (coord.). Producción y abastecimiento en el ámbito militar. Actas del II Congreso de Arqueología Militar Romana en Hispania. Lleó: 257-308.
GARcía VARGAS, E. (1996). La producción anfórica en la bahía de Cádiz como índice de romanización. Habis, 27 (Universidad de Sevilla): 49-62.

GARcía VARGAS, E. (2001). La producción de ánforas "romanas" en el sur de Hispania. República y Alto Imperio. A: Congreso Internacional Ex Baetica Amphorae. Conservas, aceite y vino de la Bética en el Imperio Romano. Sevilla-Écija, 17 al 20 de diciembre de 1998, vol. 1. Écija: 57-174.

García Vargas, E., De Almeida, R., González, H. (2011). Los tipos anfóricos del Guadalquivir en el marco de los envases hispanos del siglo I a.C. Un universo heterogéneo entre la imitación y la estandarización. Spal, 20 (Sevilla): 185-283.

Gorostidi, D., López Vilar, J., Prevosti, M., Fiz, I. (2013). Propietaris de vil.les de l'Ager Tarraconensis (meitat occidental del Camp de Tarragona). Proposta per a un catàleg. Ager Tarraconensis 5. Actes del simposi internacional. Tarragona: 401-423.

GuMÀ, M. (1992). Un rellotge de sol d'època republicana trobat a Darró. Miscel-lània Penedesenca, 16 (Institut d'Estudis Penedesencs): 145-157.

Guitart, J., Palet, J. M., Prevosti, M. (2003). La Cossetània oriental de l'època ibèrica a l'antiguitat tardana: ocupació i estructuració del territori, A: Guitart, J., Palet, J. M. i Prevosti, M. (coords.). Territoris antics a la Mediterrània i a la Cossetània oriental. Actes del Simposi Internacional d'Arqueologia del Baix Penedès (El Vendrell, del 8 al 10 de novembre de 2001). Generalitat de Catalunya. Barcelona: 129-157.

López Mullor, A., Martín, A. (2006). Tipologia i datació de les àmfores tarraconenses produïdes a Catalunya. Homenatge a Ricard Pascual i Guasch, Monografies 8. Barcelona: 33-188.

López Vilar, J. (2006). El poblament rural del camp de Tarragona en època romana: assaig de síntesi. Butlletí Arqueològic, èp. V, núm. 28. Reial Societat Arqueològica Tarraconense. Tarragona: 97-135.

Macias, J. M. (2005). Els assentaments romans com a espai de residència: l'exemple del territorium de Tàrraco. Cota Zero, 20 (Vic): 78-86.

Margenat, F., Moro, A. (1981). Donació d'un rellotge de sol romà. Butlletí del Museu de Rubi, 2.

Márquez, J. C., Molina, J. (2005). Del Hiberus a Carthago Nova. Comercio y epigrafía anfórica grecolatina. Col-lecció Instrumenta 18. Universitat de Barcelona.

Miret, J. (2005). Les Sitges per emmagatzemar cereals. Algunes reflexions. Revista d'Arqueologia de Ponent, 15. Universitat de Lleida: 319-332.

Olesti, O. (1997). El origen de las 'villae' romanas en Catalunya. Archivo Español de Arqueología, 70 (Madrid): 71-90. 
Palet, J. M. (2003). L’organització del paisatge agrari al Penedès i les centuriacions del territori de Tàrraco: estudi arqueomorfològic. A: Guitart, J., Palet, J. M. i Prevosti, M. (coords.). Territoris antics a la Mediterrània i a la Cossetània oriental. Actes del Simposi Internacional d'Arqueologia del Baix Penedès (El Vendrell, del 8 al 10 de novembre de 2001). Departament de Cultura de la Generalitat de Catalunya: 211-229.

Palet, J. M. (2007). Formes del paisatge i trames centuriades al Camp de Tarragona: aproximació a l'estructuració del territori de Tarraco. A: Remolà, J. A. (coord.). El territori de Tarraco: vil.les romanes del Camp de Tarragona, Fòrum. Temes d'Història i d'Arqueologia Tarragonines 13. MNAT. Tarragona: 49-64.

Prevosti, M. (2007). Estudi del poblament rural de l'ager Tarraconensis. Una aplicació a la Cossetània oriental. A: Remolà, J. A. (coord.). El territori de Tarraco: vil.les romanes del Camp de Tarragona, Fòrum. Temes d'Història i d'Arqueologia Tarragonines 13. MNAT. Tarragona: 65-93.

Prevosti, M. (2010). La ciutat de Tarraco entre nucli urbà i territori. A: Prevosti, M. i Guitart, J. (dir.). Ager Tarraconensis. Vol. 1: Aspectes històrics i marc natural. Documenta 16. ICAC. Tarragona: 25-111.

Principal, J. (2005). Las cerámicas del círculo de la Campaniense B. A: Introducción al estudio de la cerámica romana. Una breve guía de referencia. Universidad de Málaga: 47-62.

Py, M. (dir.) (1993). Dicocer. Lattara 6. Lattes.

Rabanal, M. A., Abascal, J. M. (1985). Inscripciones romanas de la provincia de Alicante. Lucentum, IV (Universitat d'Alacant): 191-244.

Ramon Torres, J. (1995). Las Ánforas fenicio-púnicas del Mediterráneo central y occidental. Col-lecció Instrumenta 2. Universitat de Barcelona.

Ramon Torres, J. (2008). El comercio púnico en occidente en época tardorrepublicana (siglos -II/-I). Una perspectiva actual según el tráfico de productos envasados en ánforas. A: Iberia e Italia: modelos romanos de integración territorial. Múrcia: 67-100.

Revilla, V. (2000). La villa de el Vilarenc (Calafell, Tarragona): arquitectura y organización espacial de un fundus del territorio de Tarraco. A: Ruiz DE Arbulo, J. (ed.). TÀRRACO 99. Arqueologia d'una Capital Provincial Romana. Documents d'Arqueologia Clàssica 3. Tarragona: 257-273.
Revilla, V. (2007). Production céramique, systèmes agraires et peuplement dans le territoire de Tarraco. A: Pottery workshops and agricultural productions. Studies on the rural world in the roman period- 2. Girona: 83-113.

Revilla, V. (2010). Cultura material y poblamiento en el territorio de Tarraco: los contextos cerámicos de la villa del Vilarenc (Calafell). A: Revilla, V. i RocA, M. (ed. científics). Contextos ceràmics $i$ cultura material d'època augustal a l'occident romà. Actes de la reunió celebrada a la Universitat de Barcelona (15 i 16 d'abril de 2007). Universitat de Barcelona. Barcelona: 198-221.

Roca, M. (2005). Terra Sigillata Itálica. A: RocA, M., FERNÁNDEZ, M. I. (coords.). Introducción al estudio de la cerámica romana. Una breve guía de referencia. Universidad de Málaga: 81-114.

RoIG, J. F. (2015). Memòria dels treballs arqueològics motivats pel "Projecte d'urbanització Sector S-16 La Devesa" al Vendrell (El Vendrell, Baix Penedès). Memòria d'intervenció arqueològica inèdita dipositada a la Direcció General del Patrimoni Cultural. Generalitat de Catalunya. Tarragona.

Ros, A. (2004). El món ibèric tardà i la romanització al Penedès. Fonaments, 10/11 (Barcelona): 213-244.

Sabaté, G. (1987). Algunes troballes arqueològiques als voltants de la vila del Vendrell. Miscel-lània Penedesenca, 1987 (Institut d'Estudis Penedesencs): 23-30.

SÁez Romero, A. (2008). La producción de ánforas del área del Estrecho en época tardopúnica (siglos -III a -I). A: Cerámicas hispanorromanas. Un estado de la cuestión. Cadis: 491-515.

SÁnchez, E., JÁRREgA, R. (2008). La vil.la romana de Mas d'en Gras (Vila-seca, Tarragona). Hic et Nunc 3. ICAC. Tarragona.

Solé, J. (1952). Inventario nacional de folios de arqueología. Noticiario Arqueológico Hispánico, I (Madrid): 173-251.

TARrats, F. (1992). Terra sigillata del Passatge de Cobos (Tarragona): les marques de terrisser. Miscel-lània arqueològica a Josep M. Recasens. Tarragona: 155-176.

VIVAR, G. (2005). La Cerámica Campaniense A. A: RoCA, M., FERnÁndez, M. I. (coords.). Introducción al estudio de la cerámica romana. Una breve guía de referencia. Universidad de Málaga: 23-46. 